M. Jametti, A. Redonda, A. Sen

The power to pass on taxes : a test for tax shifting based on observables

Quaderno N. 13-01

Decanato della Facoltà di Scienze economiche

Via G. Buffi, $13 \mathrm{CH}-6900$ Lugano 


\title{
The Power to Pass on Taxes - A Test for Tax Shifting based on Observables*
}

\author{
Mario Jametti ${ }^{\dagger}$ \\ Agustin Redonda \\ University of Lugano, Switzerland \\ CESifo \\ University of Lugano, Switzerland
}

Anindya $\operatorname{Sen}^{\S}$
University of Waterloo, Canada

May 16, 2013

\begin{abstract}
Since gasoline has a relatively inelastic demand, raising government revenue via gasoline taxes could appear appropriate as it entails a relatively small deadweight loss. However, gasoline retail is generally a highly concentrated market, hence the assumption of perfect competition when considering tax incidence might be misleading. Theoretically, in oligopolistic markets taxes can be shifted forward less (more) than proportionally to retail prices; a possibility usually denoted by undershifting (overshifting). Generally, this depends on unobservable parameters of the demand and cost functions. In this paper we device a novel empirical test, based on observables, to assess whether taxes are under- or overshifted in an oligopolistic market. The test depends on the interaction between market structure and taxes. We apply our test to the Canadian retail gasoline market using a panel data set of 10 cities, finding that gasoline taxes are undershifted.
\end{abstract}

Keywords: Tax Incidence; Pass-through; Market Structure

JEL classification: H22; D43; L13

$<$ All tables at end $>$

${ }^{*}$ We thank Marius Brülhart, Tilman Klumpp, Stephan Litschig, Gilbert Metcalf, Erich Muehlegger and Thomas von Ungern-Sternberg, and conference and workshop participants at CPEG (Montreal), SIEP (Pavia), YSEM (Bern), PCS (New Orleans), Sinergia Workshops (Basel, Lugano), Swiss Economic Institute - KOF (Zurich), and at the University of Luzern for particularly helpful comments. Financial support from the Swiss National Science Foundation (grant Sinergia 130648) is gratefully acknowledged. We are also solely responsible for any remaining errors or omissions.

${ }^{\dagger}$ Institute of Economics (IdEP), University of Lugano, Via G. Buffi 6, 6904 Lugano, Switzerland; e-mail: mario.jametti@usi.ch. Also affiliated with the Swiss Public Administration Network (SPAN).

${ }^{\ddagger}$ Corresponding author. Institute of Economics (IdEP), University of Lugano, Via G. Buffi 6, 6904 Lugano, Switzerland; e-mail: agustin.redonda@usi.ch. Also affiliated with the Swiss Public Administration Network (SPAN).

${ }^{\S}$ Department of Economics, University of Waterloo, Hagey Hall of Humanities, Waterloo, Ontario, Canada; e-mail: asen@uwaterloo.ca. 


\section{Introduction}

Most countries tax gasoline, although to varying degrees. Since gasoline has a relatively inelastic demand, raising government revenue via gasoline taxes could appear appropriate as it entails a relatively small deadweight loss. However, gasoline retail is generally a highly concentrated market leading to prices that are significantly above marginal cost. Hence, tax incidence analysis based on the assumption of perfectly competitive markets might be misleading. Whereas in long-run equilibrium, under perfect competition, taxes are passed on fully to consumers (are fully shifted), the situation in oligopolistic markets is different. Taxes can either be shifted forward less or more than proportionally to retail prices, i.e. they can be under- or overshifted.

The condition whether taxes are under- or overshifted depends theoretically on parameters of the demand and cost functions. These are often unobservable to the econometrician or inherently difficult to estimate. In this paper we devise a novel empirical test, based on observables, to identify whether a market presents under-, full or overshifting. We show that whether a particular market displays under- or overshifting can be assessed by the sign of an interaction term between taxes and market structure. We then take our test to data. We use a dataset on the Canadian retail gasoline market comprising monthly observations from 10 Canadian cities over the 1991-1997 period. In Canada gasoline is taxed both at the federal and provincial levels. The market is dominated by a few vertically integrated national (global) players implying a significant level of market concentration. This also holds at the local level possibly due to cost advantages from vertical integration or other barriers to entry. Both variation across time (including several provincial tax changes) and across location help us identifying our coefficients of interest.

Our results suggest that the direct effect of taxes is not statistically different from 1 indicating, in line with theory, that, under perfect competition, gasoline taxes in the Canadian retail market are fully shifted to consumers. Similarly, as expected, an increase in market concentration - measured through changes to city specific Herfindahl-Hirschman Indices - 
raises prices. Our main coefficient of interest, the interaction term between the HerfindahlHirschman Index and excise taxes, is negative and, in most specifications, statistically significant. This implies that taxes in the Canadian retail gasoline market are undershifted. We apply a series of robustness checks including alternative specifications for inference and controlling for the potential endogeneity of taxes and market structure. Our results are largely confirmed.

Assessing tax incidence in the gasoline market is of particular concern for policy analysis. First, gasoline is an important input. Moreover, in recent years, gasoline taxation has been one of the main tools to encourage rolling $\mathrm{CO} 2$ emissions back. ${ }^{1}$ Finally, the international turmoil that started in 2008 has considerably increased pressure on governments all around the world in order to reduce budget deficits. From this point of view, gasoline taxes might play an important role as a source of revenues for both local and central governments. ${ }^{2}$

Further, we would argue that our results point to a, potentially important, omission in earlier analysis of tax incidence in oligopolistic markets. First, most empirical applications either implicitly or explicitly assume perfectly competitive markets or they cursory control for market structure (via a main effect). We show that not accounting for the interdependence of market structure and taxes by not including an interaction term might result in a misspecified model. In our study, not accounting for the differential effect of taxes depending on market structure results in an underestimation of tax incidence (evaluated at the mean) of around 20\%. Similarly, in our sample, tax incidence varies from not significantly different from full absorption by producers in the most concentrated markets, to not significantly different from full shifting in the least concentrated ones. Thus, policy conclusions might need to be adapted depending on the degree of (local) market concentration. Finally, a point estimate of tax incidence without appropriately controlling for market structure might produce a coefficient larger than but not statistically different from one. Such an estimate might lead authors to conclude that taxes are fully shifted, when indeed they are overshifted. We would argue that

\footnotetext{
${ }^{1}$ See, for example, Palazzi (2011).

${ }^{2}$ As mentioned in the OECD Tax Database, currently around $4 \%$ of total tax revenue in Canada comes from environmentally related taxes.
} 
our test is a more precise instrument to assess tax incidence leading to potentially improved policy conclusions.

The rest of the paper is structured as follows. In section 2 we present the existing literature in the field. Section 3 presents the theoretical model behind our empirical analysis and derives the empirical test formally. Section 4 gives a brief description of the gasoline industry and taxes in Canada. In section 5 we describe our dataset and the empirical framework. In section 6 , we discuss our main results and illustrate the potential of inadequate policy conclusions. Finally, in section 7 , we provide some concluding remarks.

\section{Literature Review}

Krzyzaniak and Musgrave (1963) were among the first to suggest that in oligopolistic and monopolistic markets taxes could be overshifted to final prices. Subsequently, a number of theoretical papers have taken up this point. ${ }^{3}$ Katz and Rosen (1985) show that the Krzyzaniak-Musgrave result can be rationalized in a standard neoclassical model. They find that assuming competitive or monopolistic markets when indeed a sector is imperfectly competitive can lead to bias in the estimation of tax incidence. Further, they illustrate that tax incidence depends on market structure. Similarly, Seade (1985) questions the role of the perfect competition hypothesis and introduces a cost-side shifter in the equilibrium solution of an oligopolistic market. He shows that, given a certain level of market concentration, a tax hike may indeed increase the producer's equilibrium net price. Under oligopoly and assuming linear costs, price overshifting turns out to be a likely scenario. Overshifting will occur "if and only if the elasticity of the slope of inverse demand $(E)$ is greater than 1 ". 4 Note that this is always the case for an isoelastic demand.

Besley (1989) extends Seade's paper by allowing for entry in the market. His main interest is on welfare effects finding that, with entry, taxes in oligopolistic markets can be welfare

\footnotetext{
${ }^{3} \mathrm{~A}$ more detailed review can be found in Fullerton and Metcalf (2002).

${ }^{4}$ Seade (1985), p.28.
} 
improving. Regarding the extent of the shifting of taxes, he finds that there is undershifting if the demand function is concave and there is overshifting if it is convex. Also, overshifting is more likely under free entry. Delipalla and Keen (1992) compare the incidence of excise and ad valorem taxes in two oligopoly models, with and without free entry. They find that ad valorem taxes strictly dominate excise ones in welfare terms. Further, they find that under both the Generalized Cournot and Free Entry Oligopoly models, specific taxes are more likely to be overshifted than ad valorem ones.

Finally, Anderson et al. (2001) extend Delipalla and Keen (1992) by studying the incidence of ad valorem and excise taxes in an oligopolistic industry allowing for product differentiation and price-setting firms ̀̀ la Bertrand. They analyze the effects of tax incidence on prices and profits in both the short and long runs finding, again, that the conditions for overshifting depend on the curvature of the demand function. Interestingly, their results are very close to those of a Cournot model with homogeneous products.

Summarizing these contributions, the pass-through of taxes or the presence of underor overshifting generally depends on the functional form of the demand and the cost functions, i.e parameters that are not directly observable to the econometrician. Based on the theoretical literature above we derive, in the following section, a test to detect whether a particular market displays under- or overshifting which depends on observables, namely on the interaction between taxes and market structure.

Tax incidence and market structure have also been studied empirically. Early contributions are Harris (1987) and Karp and Perloff (1989). Harris (1987) studies the 1983 federal cigarette tax increase in the United States. He finds that the $36 \%$ increase in the real price of a pack of cigarettes (adjusted for general inflation) was mainly explained by the augmentation of prices charged by the major U.S. manufacturers and not by the increase in the federal excise tax. Karp and Perloff (1989) focus on the Japanese television market using data on a subset of firms. They combine firm specific information with industry aggregates to obtain estimates of market structure, while allowing for cost differences across types of TV sets. The authors find that assuming a competitive Japanese television industry underestimates 
consumer tax incidence by around $19 \%$.

Besley and Rosen (1999) examine the incidence of sales taxes for 12 commodities in 155 U.S. cities over the period 1982-1990 and examine the extent to which differences in tax rates and bases are reflected in prices. They find variation in the shifting patterns. For some commodities they cannot reject full shifting but for others they find overshifting. Additionally, they find that the response of prices to a variation in taxes is fast, i.e. there is a lag of about one quarter from the tax variation to the observed impact on prices.

Delipalla and O'Donnell (2001) analyze the incidence of ad valorem and specific taxes in the European cigarette market. They use their results as a method for estimating market power and measuring the degree of competition. Basing their analysis on data from the 12 members of the E.U., prior to its expansion in 1995, they find that commodity taxes are not always fully shifted to consumers. Indeed, after splitting the sample of countries in two different groups, they find that taxes are overshifted in southern European countries but, on the other hand, there is undershifting in the north of Europe, where the pressure of the health lobby is stronger. Moreover, their results reject both extremes, i.e. perfect competition and collusive behavior. "Firm's behavior in these markets would appear to be no less competitive than the equivalent Cournot and are probably more competitive than this." 5 DeCicca et al. (2010) study the shifting of cigarette excise taxes using data on reported prices paid for cigarettes. They focus on the impact of price-search behavior and find that cigarette excise taxes may be differentially shifted across groups of consumers. Excise taxes are shifted at lower rates to consumers who undertake more price search behavior and are shifted at higher rates to non-daily, less addicted and light cigarette smokers. Bergman and Hansen (2010) study the tax shifting of excise taxes on alcoholic and non-alcoholic beverages using micro-level data from Denmark. They focus on six episodes of tax changes including both increases and tax cuts. They find evidence suggesting large differences across brands and different types of beverages but, in general, tax increases are overshifted whereas tax cuts are undershifted. They interpret their results as evidence of Danish retailers having substantial

\footnotetext{
${ }^{5}$ Delipalla and O’Donnell (2001), p.21.
} 
local market power.

Three papers among the large literature on gasoline tax incidence are of particular interest for our study. Chouinard and Perloff (2007) study price differences across U.S. states. They find that most of the increase in national gasoline prices over the 1990s is explained by a rise in the price of crude oil. Thus, the authors find that other factors such as taxes and market power did not have a significant impact on the price increase observed during that decade. On the other hand, differences among states in retail gasoline prices are largely explained by variations in taxes and market power. DiGiacomo et al. (2012) analyze the incidence of excise taxes in fuel markets and exploit their findings to simulate the effects of government interventions aimed at mitigating oil price fluctuations. They use wholesale prices for gasoline and diesel in the Italian fuel industry over the period 1996-2007, finding evidence supporting that "flexible" taxation schemes focusing only on excise taxes do not stabilize the fuel price level. Moreover, they mention policies focused on market structure such as the role of the Antitrust Authority as alternative interventions in order to control price fluctuations. More recently, Marion and Muehlegger (2011) analyze the pass-through rate of federal and state gasoline and diesel taxes to retail prices, focusing on the dependence of the shifting on factors constraining the gasoline and diesel supply chains. They find full pass-through of both state and federal taxes for both gasoline and diesel in most of their specifications. In addition, the authors find that the observed pass-through is immediately translated into final prices. Contrary to our study, none of these papers consider the interplay between the effect of taxes and market structure explicitly and most of them do not even control for market structure. Indeed, some papers implicitly (or explicitly) make the assumption of perfectly competitive markets.

The closest study to ours is Sen (2001). He investigates the presence of overshifting in cigarette retail prices using data for 10 Canadian provinces from 1982 to 2002. He focuses on whether the presence of overshifting can be attributed to signs of collusion in the industry. The author finds overshifting of provincial taxes but not of federal ones. Moreover, he cannot attribute the overreaction of prices to provincial taxes directly to collusion. We abstract from 
the collusion hypothesis, but focus instead on the interdependence of market structure and tax incidence which is, once again, absent in Sen's paper.

\section{Theoretical model}

We base our test on a simple Cournot oligopoly model based on Besley (1989) where $N$ firms in the industry choose their level of output taking prices and taxes as given. Firms are symmetric and, for simplicity, we take the number of firms as exogenously given, but perform comparative statics. Finally, we concentrate on the effect of excise taxes, the main tax instrument in our dataset. ${ }^{6}$

Let the inverse demand function be:

$$
p\left(\sum q_{i}\right) \equiv p(Q)
$$

where $p$ is the consumer price, $q_{i}$ is the output of firm $i$ and $Q\left(\equiv \sum q_{i} \equiv q_{i}+Q_{-i}\right)$ denotes the total output of the industry. ${ }^{7}$

The profit function of firm $i$ is given by:

$$
\pi_{i}\left(q_{i}\right)=p\left(q_{i}+Q_{-i}\right) q_{i}-c\left(q_{i}\right)-\tau q_{i}
$$

where $\tau$ is an excise tax on $q$ and $c\left(q_{i}\right)$ is the cost function.

Standard assumptions are imposed in order to assure a stable symmetric Cournot equilibrium:

Assumption 1. $p(Q): \Re^{+} \rightarrow \Re^{+}$is twice continuously differentiable and $p^{\prime}(Q)<0$ for all $Q$ such that $p(Q)>0$.

\footnotetext{
${ }^{6}$ The model can be extended in many directions such as allowing for entry into the industry (Besley (1989)) or adding an ad valorem tax (Delipalla and Keen (1992)).

${ }^{7} Q_{-i}$ denotes the output of the industry produced by all the other firms but firm $i$.
} 
Assumption 2. $c(q): \Re^{+} \rightarrow \Re^{+}$is increasing and twice continuously differentiable with $c(0)>0$, i.e. all firms face a fixed cost.

Since we are focusing on symmetric equilibria, we can omit the subscripts and derive the first and second order conditions of the profit maximizing firm:

FOCs: $p^{\prime}(Q) q+p(Q)-c^{\prime}(q)-\tau=0$,

$$
\text { SOCs: } p^{\prime \prime}(Q) q+2 p^{\prime}(Q)-c^{\prime \prime}(q)<0 \text {. }
$$

We can re-express (4) as:

$$
\frac{p^{\prime}(Q)}{N}(\eta+N+N k)<0,
$$

where, as defined by Seade (1980), $\eta=\frac{Q p^{\prime \prime}}{p^{\prime}}$ is the elasticity of the slope of the inverse demand and $k=1-\frac{c^{\prime \prime}}{p^{\prime}}$ represents the relative slopes of the demand and marginal cost curves. $^{8}$

Since $p^{\prime}<0$, we get the following necessary and sufficient condition for the SOCs to hold:

$$
\eta+N+N k>0 .
$$

Now, given symmetric firms:

$$
p(Q) \equiv p\left(q_{i}+Q_{-i}\right) \equiv p(N q),
$$

plugging (7) into the FOCs:

$$
p^{\prime}(N q) q+p(N q)-c^{\prime}(q)=\tau .
$$

\footnotetext{
${ }^{8}$ We treat $\eta$ and $k$ as parameters, abstracting from second-order effects of $N$ and $\tau$ around equilibrium.
} 
Differentiating (8) with respect to $\tau$ and rearranging, we obtain:

$$
\frac{\partial q}{\partial \tau}=\frac{1}{p^{\prime}(\eta+N+k)}
$$

and

$$
\frac{\partial Q}{\partial \tau}=\frac{N}{p^{\prime}(\eta+N+k)} .
$$

Therefore,

$$
\frac{\partial p}{\partial \tau}=p^{\prime}\left(\frac{\partial Q}{\partial \tau}\right)=\frac{N}{N+(\eta+k)}
$$

Proposition 1. Under perfect competition $(N \rightarrow \infty)$ taxes are fully shifted onto consumers $\left(\frac{\partial p}{\partial \tau} \rightarrow 1\right)$. As the market gets more concentrated, the degree of shifting $\left(\frac{\partial p}{\partial \tau}\right)$ moves away from one (1). Indeed, under monopoly $(N \rightarrow 1)$, the degree of shifting is the largest in absolute value.

Proof. Inspection of (11) immediately proves Proposition 1.

Equation (11) confirms that, under perfect competition, taxes are fully passed to consumers. Moreover, it shows that $\left|\frac{\partial p}{\partial \tau}\right|-1$ is the largest for $N=1$, i.e. under monopoly the degree of shifting is always the furthest away from one. We can now look at the conditions for under- respectively overshifting.

Proposition 2. If $(\eta+k)$ is positive, $\frac{\partial p}{\partial \tau}<1$ and the market undershifts taxes. On the other hand, if $(\eta+k)$ is negative, $\frac{\partial p}{\partial \tau}>1$ and we are in the presence of overshifting.

Proof. Inspection of (11) allows us to classify the cases of relevance for our analysis:

$$
\frac{\partial p}{\partial \tau}=\frac{N}{N+(\eta+k)} \begin{cases}<1 & \Rightarrow \text { undershifting } \\ =1 & \Rightarrow \text { full shifting } \\ >1 & \Rightarrow \text { overshifting }\end{cases}
$$


Proposition 3. The sign of $(\eta+k)$ equals the sign of the cross derivative of prices with respect to taxes and market structure.

Proof.

$$
\frac{\partial\left(\frac{\partial p}{\partial \tau}\right)}{\partial N}=\frac{(\eta+k)}{(\eta+N+k)^{2}}
$$

As $(\eta+N+k)^{2}>0$ for all $\eta, N$ and $k$, the sign of (13) equals the sign of $(\eta+k)$.

Corollary. Let HHI be an inverse function of $N$. Then,

$$
\frac{\partial\left(\frac{\partial p}{\partial \tau}\right)}{\partial H H I} \simeq \frac{-(\eta+k)}{(N+(\eta+k))^{2}}
$$

Proposition 3 and its Corollary summarize the main contribution of our paper. As mentioned in Proposition 2, the sign of $(\eta+k)$ tells us whether we are in presence of under- or overshifting. Both $\eta$ and $k$ depend on the underlying parameters of the demand and cost functions and are therefore unobservable or inherently difficult to estimate. However, Proposition 3 shows that the sign of the cross-derivative of prices with respect to taxes $(\tau)$ and the number of firms $(N)$ is equal to the sign of $(\eta+k)$. The empirical counterpart of this cross-derivative is an interaction term of taxes and market structure in a regression equation. Now, as is usual in an empirical context, market structure is often characterized by a concentration measure, such as the Herfindahl-Hirschmann Index (HHI), which is an inverse function of $N$. The Corollary shows that the interaction term of taxes with a concentration measure indicates the opposite sign of $(\eta+k)$.

Our framework allows to test whether taxes are under- or overshifted in a particular market based on observables. Indeed, in a price-regression framework the sign of the coefficient of the interaction term between taxes and market concentration will inform about tax incidence. If the interaction term has a negative coefficient taxes are undershifted, while if its sign is positive taxes are overshifted. An empirical application of our test is straightforward and requires variation in taxes and market structure in the relevant product market. 


\section{The gasoline industry and taxes in Canada ${ }^{9}$}

The retail gasoline market in Canada is composed of three different categories of firms: major vertically-integrated, regional and independent firms. Vertically-integrated firms such as Petro-Canada, Shell and Esso conduct crude exploration, production and development operations as well as downstream refining and retailing, operating at a national level. Regional firms also conduct integrated upstream and downstream activities but are geographically limited. For instance, Irving Oil and Ultramar operate in eastern Canada, whereas Husky is located in the Prairies and the West. Together, majors and regionals account for roughly $80 \%$ of all retail sales. Finally, independent firms (e.g. Cango in Ottawa and Domo in Vancouver) and super store retailers (Canadian Tire, Real Canadian Superstore, Save on Foods and Costco) do not own refineries and exclusively conduct downstream retailing.

Retailers considerably decreased during the 1990s from 22.000 in 1989 to 13.250 in 2000, i.e. a reduction of around $40 \%$. Although majors have led the rationalization in terms of retail outlets and independents increased their proportion of retail sites, the market share of the latter ones decreased from $23 \%$ in 1990 to $18 \%$ in 1999 suggesting an increase in the degree of market concentration. ${ }^{10}$ These stylized facts are consistent with the following observation noted by the Board's report "the gasoline industry in Canada has a limited number of key players who, through their vertical integration and sheer size, are often expected to have power in the marketplace [and] differences in gasoline prices between cities are generally influenced by the different competitive conditions found at the street level."11

Finally, as mentioned in the same report, besides the barriers to entry that are usually present in the gasoline industry (such as economies of scale and capital requirements), costs to both entering and exiting the retail business considerably increased during the 1990s. New environmental regulations were implemented increasing the cost of opening a retail outlet and entry was discouraged by decreasing retail margins throughout most of the decade.

\footnotetext{
${ }^{9}$ This section is based on the comprehensive review conducted by The Conference Board of Canada. The report gives an overview of the industry during the 1980s and 1990s covering the sample period of our analysis.

${ }^{10}$ See also Sen and Townley (2010).

${ }^{11}$ The Conference Board of Canada (2001), piii.
} 
Taxes are the largest component of the pump price in Canada. In 2000, retail gasoline prices consisted of three major components: taxes, crude oil and a refining/marketing component with taxes representing, on average, around $42 \%$ of the price. Gasoline taxes in Canada can be divided as follows: federal and provincial excise taxes; the Goods and Services Tax (GST); as well as the Provincial Sales Taxes (PST), where applicable. The federal excise tax is imposed across Canada and added on to the other price components of gasoline (crude oil, refining margin and retail margin). In addition, a similar (excise) tax on gasoline is also levied by provincial governments. Moreover, the GST is levied on all components of the price of gasoline. All Canadian provinces pay the GST, although for New Brunswick, Nova Scotia and Newfoundland it is part of the Harmonized Sales Tax (HST). Quebec is the only province in Canada to explicitly charge a Provincial Sales Tax (PST). The PST is an ad valorem tax and is calculated on the total cost of gasoline. Finally, some Canadian cities apply their own transit (flat) taxes on retail gasoline.

To sum up, although roughly $80 \%$ of sales belong to national and regional retailers, concentration varies across cities and time likely due to differences in market shares of independent and super store retailers. Moreover, gasoline is taxed both at the federal and provincial levels. Provinces are completely free to set their taxes, implying significant variation across cities. Hence, Canada presents an almost ideal setting to test our theory.

To illustrate the variation in our raw data we have divided Canada in four geographical regions: Eastern Canada, Quebec, Ontario and Western Canada. Figure 1 illustrates the evolution of (final) retail prices for the four regions. All of them show decreasing retail prices at the beginning of the period and an increasing trend afterwards. Though the inflection year varies for the different regions, i.e. while final prices in Western Canada started increasing in 1992; in Quebec they started augmenting only in 1995. Moreover, taking the two extremes of the time line covered by our sample (1991 and 1997), we observe that final prices in both Eastern Canada and Ontario remained almost constant while they increased in Western Canada and diminished in Quebec.

In the left panel of Figure 2 we display the evolution of market concentration (measured 
by the Hirschmann-Herfindahl Index, HHI) across the period covered in our dataset. ${ }^{12}$ Interestingly, we observe different patterns. The highest concentration is found in Eastern Canada with HHI values above 2'000, although with a slight decrease of concentration over time. All other regions have witnessed rationalisation over the period, implying increasing concentration levels. The steepest wave of concentration belongs to Quebec, holding the lowest levels of market concentration (HHI below 1400) at the beginning of the 1990s, but ending up with an HHI close to 2'000 by 1997. Both Ontario and Western Canada experienced market concentration but at lesser rates than Quebec. On the right panel of Figure 2 we plot the evolution of excise taxes (in cents per litre) for the four regions. Taxes have generally increased over the period but at differing rates across regions. While Eastern Canada taxed gasoline at the highest levels in 1991, they were overtaken by Quebec and Ontario subsequently. Also noteworthy is that the spread of excise taxes has slightly increased over time by roughly one cent per litre. Figure 3 illustrates the relation between final prices and market concentration (left panel) and excise taxes (right panel). Both variables display a positive effect on prices, as expected. The raw correlation coefficients are 0.27 for market concentration and 0.43 for taxes.

Finally, Figure 4 illustrates graphically our test. We plot again the relation between taxes and prices dividing the sample into low and high concentrated markets. ${ }^{13}$ Further, we fit a simple regression line through the scatter plot for each type of market. In the graph, our test corresponds to comparing the slope coefficients of the fitted lines between low and high concentrated markets (indicated in the figure). We observe that the passthrough of taxes to final prices is slightly lower for high concentrated markets (0.76) than for low concentrated ones (0.81). Thus, the effect of taxes on prices decreases with market

\footnotetext{
${ }^{12}$ The Hirschmann-Herfindahl Indeces are computed as the sum squared of firm specific market shares and are a common measure of market concentration used by antitrust agencies such as the Federal Trade Commission and the Department of Justice, especially with respect to merger analysis. HHI are computed as the sum of squared individual firm specific market shares. Hence, a monopoly would result in an HHI of 10,000. As detailed in the U.S. Department of Justice's website (http://www.justice.gov/atr/public/guidelines/hhi.html), antitrust agencies generally consider markets in which the HHI is between 1,500 and 2,500 points to be moderately concentrated, and markets in which the HHI is in excess of 2,500 points to be highly concentrated.

${ }^{13}$ The sample is divided along the median.
} 
concentration, suggesting that the Canadian retail gasoline market undershifts taxes.

In the following sections, we intend to study the relationship between prices, excise taxes and market concentration using formal econometric models.

\section{$5 \quad$ Data and empirical framework}

\subsection{Data}

Our dataset consists of monthly observations for the period 1991-1997 of ten of the main cities in Canada. ${ }^{14}$ The three main variables are those concerning gasoline prices, taxes and the gasoline retail market structure. We obtained retail prices (the dependent variable) from the Weekly Pump Price Survey (WPPS) of MJ Ervin \& Associates. ${ }^{15}$ This is a survey of prices for retail gasoline in more than 50 Canadian cities. We use city-level monthly averages and prices are final pump prices including all taxes. ${ }^{16}$

Our main tax variable, excise, accounts for federal and provincial excise taxes. ${ }^{17}$ Information on market concentration and the number of stations was obtained from The Kent Group, a private consulting company providing this information from all outlets in the markets it surveys. We use the standard Hirschmann-Herfindahl Index $(H H I)$ as our market concentration measure.

We include a number of control variables as well. Gasoline wholesale prices and the

\footnotetext{
${ }^{14}$ The cities in our database are: Calgary, Halifax, Montreal, Ottawa, Quebec, Saint John, St. Johns, Toronto, Vancouver and Winnipeg.

${ }^{15} \mathrm{MJ}$ Ervin \& Associates is a division of the Kent Group.

${ }^{16}$ Such taxes include the Goods and Services Tax (GST). Since the GST is also applied to excise taxes, one could argue that using final prices biases our results towards finding overshifting of taxes as any (excise) tax increase would be multiplied by one plus the GST into final prices. We are not particularly worried about this issue, mainly because the GST is a level effect and it is not clear that it should affect our coefficient of interest, namely the interaction of taxes and market structure. We would, indeed, argue that this could be seen as an advantage of our test.

${ }^{17}$ We restrict our analysis to variation of provincial and federal excise taxes as the ad valorem sales tax component, whether in terms of GST, PST or HST is a relatively small portion of final per litre retail prices. Indeed, our summary statistics show that excise taxes constitute $62 \%$ of final retail prices. Nevertheless, as a robustness check, we also carried out the estimations using two additional tax variables: state that only accounts for excise taxes at the provincial level and both, a broader tax variable including federal and excise taxes and the goods and services tax (GST) converted into dollar equivalents. Results do not significantly differ and are available upon request.
} 
number of gasoline stations control for supply-side characteristics. The wholesale price is also reported in the WPPS and is highly correlated with crude oil price suggesting that it captures both the effects from the Canadian wholesale and the international crude oil markets. Thus, we decided not to include crude oil price as a regressor. Finally, we also control for demand side aspects by including per capita gasoline consumption, average income at the provincial level and demographic controls (provincial unemployment rates, population, percentage of youths between 15 and 24 years old). Table 1 presents summary statistics.

\subsection{Empirical framework}

We estimate the following model:

$$
\text { Price }_{i t}=\beta_{0}+\beta_{1} \text { Excise }_{i t}+\beta_{2} H H I_{i t}+\beta_{3} \text { Excise }_{i t} * H H I_{i t}+\mathbf{X}_{i t}^{\prime} \beta+\epsilon_{i t},
$$

where Price $_{i t}$ denotes retail prices including taxes in city $i$ at year $t$. Excise Et $_{i t}$ accounts for both federal and provincial excise taxes, $H H I_{i t}$ is the Hirschman-Herfindahl Index and $\mathbf{X}_{i t}$ is the set of control variables described above. ${ }^{18}$

Two comments to this specification regarding our theory are in order. First, equation (11) shows that the effect of taxes on prices, in general, depends on market structure $(N$ in our model). Second, our test (formulated in Proposition 3), calls for an interaction term between taxes and market structure. Thus, the inclusion of the interaction term in (14) is warranted by theory.

This is relevant, because, to our knowledge, no study of tax incidence in oligopolistic markets has included this specific interaction term $\left(\beta_{3}\right)$; not even those that do control for market structure. To say it differently, previous studies on tax incidence measure the effect of taxes on prices through the coefficient $\beta_{1}$. Similarly, in these models, $\beta_{2}$ measures the effect of market concentration on retail prices. In our case, $\beta_{1}$ measures the direct pass-through effect of taxes under perfect competition, i.e. when $H H I=0$ and $\beta_{2}$ accounts for the direct

\footnotetext{
${ }^{18}$ In order to simplify the interpretation of the estimates, we re-scale $H H I$ between 0 and 1.
} 
effect of market structure on prices when no tax is applied. We thus expect $\beta_{1}$ to be equal to 1 and $\beta_{2}$ to be positive. Finally, our main coefficient of interest is $\beta_{3}$, the coefficient of the interaction term that measures the effect of market concentration on the degree of tax shifting. From Proposition 3 and its Corollary, its empirical sign indicates whether we are in presence of under- or overshifting.

\subsubsection{Inference}

Our basic specifications present robust standard errors. However, it could be warranted to allow for other standard errors structures. A typical issue when working with time series (or panel data) is the presence of serial correlation. Newey-West standard errors allow the error structure to be heteroskedastic and possibly autocorrelated up to some lag. Another strategy in the same direction is to fit the model using Feasible Generalized Least Squares (FGLS). This strategy allows for the presence of $\mathrm{AR}(1)$ autocorrelation within panels and cross-sectional correlation and heteroskedasticity across panels.

Another possibility is to allow the error terms to be correlated within clusters. Clustering at the city level and computing cluster-robust standard errors seems straight forward in our model. Indeed, as it has been shown by Moulton (1990), the estimation of the covariance matrix without controlling for clustering can lead to understated standard errors and overstated statistical significance. ${ }^{19}$ Under the usual assumptions, the OLS estimator is unbiased in small samples and normally distributed or consistent and approximately normally distributed when we work with a large number of clusters. In other words, the cluster-robust covariance matrix is consistent when the number of clusters tends to infinity. However, we are working with only 10 clusters. Thus the standard procedures for clustering might not be valid. An alternative is the application of the wild bootstrap method applied in Cameron et al. (2008).

\footnotetext{
${ }^{19}$ See also Moulton (1986), Wooldridge (2003) and Stock and Watson (2008) among others.
} 


\subsubsection{Endogeneity}

One could argue that two potential issues of endogeneity exist in our analysis. First, higher prices could encourage entry and thus impact market structure. Therefore, market concentration may be endogenous to prices. Second, coefficient estimates of the effects of taxes may be confounded because of simultaneity bias between taxes and prices. In other words, tax setting authorities might adjust tax rates given current prices. As such, we perform instrumental variables regression.

First, concerning market structure, we can expect $P_{i t}$ and $H H I_{i t}$ to be correlated but it is less likely that Price $_{i t}$ and $\mathrm{HHI}_{i t-1}$ or $\mathrm{HHI}_{i-2}$ are. Thus, we use the one- and twoperiods lagged value of $H H I_{i t}$ as an instrument for market structure. Similarly, following the strategy implemented by Besley and Case (2000), we instrument taxes with the political party in power at the provincial level. Specifically, we use data on the share of seats of the political party in power in each province and an indicator whether the political party in power is the same at both the federal and provincial levels. The idea behind our strategy is that political parties may influence the set of policies to be implemented (including taxation) without having any direct relationship with retail prices.

\section{$6 \quad$ Estimation and results}

\subsection{Preliminary results}

We start in Table 2 repeating, with our sample, what has currently been done in the literature, i.e. we estimate (14) without the interaction term. In column (1) we include city-specific fixed effects, while in column (2) we add quarterly dummies to capture seasonality. In column (3) we also include an overall time trend. Finally, in column (4) we omit the city level fixed

effects and the overall time trend but allow for city-specific time trends. The overall fit of our model is good with $R^{2}$ of around 0.75 .

Regarding the control variables, we observe that wholesale prices are an important deter- 
minant of retail prices. An increase of the wholesale price of 10 cents raises final prices by roughly 7 cents. Also, the impact of wholesale is rather persistent. The lagged value is still positive and highly significant, while the coefficient of the second lag is negative. The socioeconomic controls reveal the expected signs. The unemployment rate, an indicator of the economic situation of the city, reduces prices, as does a higher share of young. Population instead increases prices, likely due to increased driving distances and levels of congestion in larger cities. Similarly, average income has a positive and significant effect on prices.

Of the supply side variables, only the number of stations has a significant effect on prices. Slightly contrary to expectations, a higher number of stations raises gas prices. We presume that this result is driven by the fact that larger cities have more stations but also higher demand.

Regarding our main coefficients of interest it is interesting to note that market concentration does not seem to affect retail prices as expected. The coefficient of $H H I$ is negative but not statistically significant, suggesting that these specifications might be biased.

More importantly, excise exerts a positive and significant (at least at the 10\%-level) effect on prices across all specifications. The magnitude of the coefficient is rather small. Taking the coefficient of column (3), an increase in excise of ten cents raises the final price by roughly 2.5 cents. Evaluated at the mean this implies an elasticity of prices with respect to excise of 0.07 . These results suggest that we are in presence of undershifting and that retail prices react actually quite little to changes in taxes. However, these results do not take into account the possibility that the degree of tax shifting might vary with market concentration, to which we now turn.

\subsection{Main results}

Table 3 shows our main results. The specifications in column (1) to (4) are the same as in Table 2. All the control variables have the identical signs and similar magnitudes. Again, only gasoline consumption is not statistically significant. Hence we will not discuss controls 
again and concentrate on our main coefficients.

The direct effect of excise taxes on final prices is, statistically significant and positive in all the specifications. Further, the magnitude of the coefficient varies very little across specifications and is around 1.3. This implies, taking the coefficient values of column (3), that under perfect competition $(H H I=0)$ a 10 cent increase in excise is associated with a 13.5 cent raise in prices. Thus, the results suggest overshifting of taxes even in competitive markets, which is contrary to theory. However, in none of the specifications we can reject that the main effect of excise is actually equal to one, i.e. that taxes are fully shifted when $H H I=0$, as indicated in the last row of Table 3 , where we test for $\beta_{1}=1 .^{20}$

Similarly, the direct effect of market structure on prices is statistically significant and positive, as expected. Again, the magnitude of the coefficient is robust across specifications and is around 120. Thus, an increase in HHI of 0.1 implies a raise in prices of roughly 12 cents. $^{21}$

Most importantly, the degree of tax shifting depends largely on market structure. Indeed, the coefficient of the interaction term between excise and HHI is negative and highly statistically significant. Again, its magnitude is robust across specifications and fluctuates around -6 . This is quite an important effect. Evaluated at the mean of $H H I(=0.18)$ our results imply that a 10 cent increase in taxes is associated with a raise of 3.0 cents in final prices, a tremendous difference from the degree of tax shifting under perfect competition (13.5). Incidentally, the average effect of excise is slightly higher than the one estimated in the model without the interaction term $(=0.25)$. We return to the interpretation of the results in section 6.4 .

Based on our test, the negative sign of the interaction term between taxes and market concentration lets us conclude that excise taxes are undershifted in the Canadian retail gasoline market.

\footnotetext{
${ }^{20}$ An interpretation of $\beta_{1}>1$ could come from the fact that we are estimating out of sample, since we do not observe values of $H H I$ close to 0 in our sample (see Table 1).

${ }^{21}$ Recall that $H H I$ in the estimation is re-scaled between 0 and 1 . Hence, an increase in $H H I$ of 0.1 represent a 1000 point increase in the usual scale.
} 
Finally, one could argue that our results are driven by the unit of observation, which is the city-month. This corresponds to the variation we observe for the $H H I$. Thus, we aggregated the weekly prices we avail of. It could be suspected that both market concentration and excise taxes vary little from month to month and that our coefficients are essentially identified on the cross-section dimension. Columns (5) and (6) of Table 2 show that this is not the case. In column (5) we included year fixed effects and a full subset of city-month fixed effects. Our results, do not change qualitatively. However, this is not our preferred specification, as we reject the null hypothesis of $\beta_{1}=1 .^{22}$

Finally, in column (6) we go in the other direction and estimate our model using yearly instead of monthly averages. Again, results do not change qualitatively although we, quite obviously, loose statistical precision. ${ }^{23}$

\subsection{Robustness checks}

We performed a battery of robustness checks of our main results. Table 4 presents alternative specifications of the error structure. Column (1) repeats the results from column (3) in Table 3, which we take as our base specification for the robustness checks. In column (2) we use a random effects model. The next two columns address potential issues of autocorrelation. In column (3) we allow for Newey-West standard errors. Note that in this specification we did not include the lagged values of the wholesale price. Next, in column (4) we estimate a feasible GLS model.

Our results are robust to these alternative specifications and confirm our result that taxes are undershifted. In all of them excise taxes and market concentration exert a positive and significant impact on gasoline prices, while the interaction between these two variables is negative and highly statistically significant. Further, one can note that the magnitude of

\footnotetext{
${ }^{22}$ Furthermore, the magnitude of the coefficients of column (5) is larger for all main coefficients. By preferring the specification in column (3) we also take a somewhat conservative approach for discussion of results.

${ }^{23}$ Further, inspection of Figure 1, with the $u$-shaped evolution of prices could call for a break in the time trend. We estimated our model with a break in 1994, allowing for differential trends in these two periods. Results do not change and are available upon request.
} 
the effects is also fairly stable across specifications. The lowest magnitudes are obtained in the random effects model. Finally, in none of the specifications we reject the test of full tax shifting under perfect competition (last row of the table).

In columns (5) and (6) we cluster standard errors at the city-level. As mentioned before, this strategy seems straightforward. In column (5) we use city fixed effects, while in column (6) we use a random effects model.

Note that, when clustering standard errors, we loose statistical significance, except for excise in the random effects model. ${ }^{24}$ However, as discussed above, given that we work with a very small number of clusters (10), clustering techniques might not be adequate in our situation. Hence, we prefer our main results from Table 3.

In Table 5 we turn to the possible endogeneity issues as described in section 5.2.2. We instrument excise with the share of seats of the political party in power in each province and a dummy indicating whether the political party in power is the same at both the federal and provincial levels. Market structure is instrumented with two lags of $H H I$. The first three columns are based on FE-2SLS whereas columns (4) to (6) replicate the same specifications under a RE-2SLS approach.

In columns (1) and (4), we only instrument $H H I$, while in columns (2) and (5) we only instrument the tax variable, excise. Finally, in columns (3) and (6), we tackle both endogeneity issues at the same time instrumenting both excise and $H H I$.

Our set of instruments performs quite well in terms of weak instruments. We compute a Weak Identification Test following Stock and Yogo (2002). ${ }^{25}$ For columns (1), (2), (4) and (5); where only one endogenous variable is considered at the time, we provide the 1st-stage F-statistic. In all the four specifications the F-statistic is larger than 10 suggesting that we are not in presence of weak instruments. In columns (3) and (6), where we consider two endogenous variables silmutaneously, we provide the Cragg-Donald Wald F-statistic to be

\footnotetext{
${ }^{24}$ Using the wild-cluster bootstrap- $t$ procedure to improve inference while working with few clusters, we find the following p-values: Under the FE approach; 0.25375, 0.26873 and 0.34466 for excise, $H H I$ and the interaction term respectively. Under the RE approach the values are the following ones: $0.32068,0.44555$ and 0.69630 for excise, $H H I$ and the interaction term respectively.

${ }^{25}$ See also Hausman et al. (2005) and Baum et al. (2003).
} 
compared with the values given by Stock and Yogo (2002). In column (3), we reject the null that the set of instruments is weak at a $20 \%$ maximal IV relative bias. ${ }^{26}$ In column (6), we can reject the null that the set of instruments is weak at a $10 \%$ maximal IV relative bias.

Things are slightly more problematic in terms of the exogeneity condition. As it can be observed from Table 5, the Sargan test is passed when we only instrument for market structure. But, the exogeneity test is not passed once we instrument excise. We attribute this result to the fact that we have fairly little variation in our instruments for taxes. Not only is the political situation in the different provinces fairly stable over time but, additionally, political variables do not change over the electoral cycle (usually four years in Canada). Thus, the short time period we avail of implies we are not able to identify the coefficients with sufficient precision.

Nevertheless, turning to our main coefficients, we can observe that across all instrumented specifications our main coefficients remain statistically significant and with the expected signs. Hence, instrumenting confirms the result of our test that excise taxes are undershifted in the market under study. ${ }^{27}$ Nevertheless, as it is often the case, the FE-2SLS estimates are bigger than the FE-OLS ones. This is particularly the case when we instrument for excise. Indeed, when instrumenting for taxes in a fixed effect framework (columns (2) and (3)), our coefficients literally explode while remaining with the expected signs.

\footnotetext{
${ }^{26}$ It is worth mentioning that, although we do not have other values than the one provided by Stock and Yogo (2002), we would probably also reject the null at a 15\% maximal IV relative bias given that the CraggDonald Wald F-statistic of 7.93 has to be compared with the following values: $10 \%$ maximal IV relative bias, 8.78 and $20 \%$ maximal IV relative bias, 5.91 .

${ }^{27}$ Following the procedure in Baltagi (2009), we perform two Hausman tests based on the contrast between the fixed effects and random effects estimators; one before and other after controlling for endogeneity. The idea is that the result could have changed when applying the 2SLS framework. Nevertheless, in our case, we reject the null that the RE estimator is consistent in both cases, before and after controlling for endogeneity. Hence, the FE specification is preferred to the RE one in both Table 3 and Table 5 . We show both the FE and RE estimations as an additional robustness check.
} 


\subsection{Discussion of results ${ }^{28}$}

What do our results imply? In this subsection we briefly discuss four points we consider particularly relevant: i) model specification; ii) policy conclusions; iii) generality of our test; and iv) welfare implications.

We first illustrate our results graphically. Figure 5 plots the level of tax shifting depending on market structure. It can be noted that for a large part of concentration values contained in our sample, tax incidence is statistically significantly less than one. ${ }^{29}$ Also, one can infer from the graph that full shifting cannot be rejected for perfectly competitive markets (as we have tested statistically above). Further, the graph nicely illustrates the strong effect market structure has on tax incidence. Indeed, the estimated effect for concentrated markets turns even negative at around $H H I=2300$, although this is never statistically significant.

Let us now turn to our first discussion point. As mentioned above, most empirical applications of tax incidence in oligopolistic markets did not include the interaction term between taxes and market structure, although warranted by theory. These models might be inadequately specified as our results suggest. In our sample, not controlling for the interaction term underestimates tax incidence. In column (3) of Table 2 the tax coefficient was estimated at around 0.25 while, in our preferred specification, tax incidence at the mean of market concentration is 0.30 , i.e. an increase of around $20 \%$.

However, not only tax incidence could be incorrectly estimated, also wrong policy conclusions could be taken. This takes us to the next discussion point. Taking the model of Table 2 one would conclude that only about $25 \%$ of an increase in taxes is passed on to consumers, and would apply this policy result to all the markets. However, the effective tax incidence varies greatly across different markets (and hence regions). This is again nicely illustrated in Figure 5 above. In our sample, tax incidence varies from 0.65 to (an admittedly implausible) -0.44 between the least and most concentrated markets. More importantly, looking at the inference of our coefficients, our results suggest that in the least concentrated markets (Ot-

\footnotetext{
${ }^{28}$ This section is based on our preferred specification i.e. column (3) in tables 3 and 2.

${ }^{29}$ This is the case for $H H I>1450$.
} 
tawa, Montreal, Calgary, Winnipeg and Toronto) taxes might actually be fully passed on to consumers, while they might be fully absorbed by producers in the most concentrated markets (Vancouver, Quebec, Halifax, St. Johns and Saint John). Obviously, policy conclusions might be quite different under these two scenarios.

Further, some caution should be applied when interpreting a model that does not include the interaction term. ${ }^{30}$ Suppose that estimating a model without the differential effect of taxes depending on market structure produces a coefficient on excise that is not statistically different from one. Then, one would conclude that taxes are fully shifted to consumers, confirming the implicit assumption of a perfectly competitive market.

For example, we think that our findings are relevant to the conclusions drawn by Marion and Muehlegger (2011), in a recent and important contribution to the sparse literature on tax incidence. While the main focus of their paper is not on imperfectly competitive markets, but rather on the effect of capacity constraints on tax incidence, they do estimate price regressions similar to ours for the U.S. gasoline and diesel markets. In the paper, they estimate a total of 40 pass-through rates. In most cases (in 31 out of 40 regressions) they find coefficient estimates greater than 1 , but not statistically significantly different from 1 . They conclude that "... gasoline and diesel fuel taxes are on average fully... passed on to consumers". ${ }^{31}$ However, the authors do not control for market structure. Given this, our findings raise the possibility that taxes may be overshifted in the U.S. gasoline and diesel markets. In other words, if one were to estimate a model controlling for market structure and the interaction term between taxes and market structure, one were likely to find a positive interaction term. The model by Marion and Muehlegger (2011) estimates tax incidence essentially at the mean of market structure across States. The confidence interval of this estimation does not allow them to reject full shifting leading to the confirmation of a perfectly competitive market. In Figure 6 we illustrate this alternative scenario. Let's assume taxes are overshifted, hence tax incidence increases with market concentration. However, the confidence interval of the pass-

\footnotetext{
${ }^{30}$ Although it should be noted that this is not the case in our sample.

${ }^{31}$ Marion and Muehlegger (2011), p. 1202.
} 
through rates estimated at the mean of market concentration might contain one, leading to the potentially incorrect conclusion of full shifting. It should be finally noted that the policy conclusions might be different under overshifting. For instance, consumer surplus reduction is larger (even in case of inelastic demand) and producer profits can increase when taxes are overshifted.

Of course, the above is a possibility which can only be confirmed if access to market structure data in the U.S. markets are available. However, at the very least, we would argue that our test complements Marion and Muehlegger (2011) quite nicely, in terms of being a useful instrument to assess the degree of tax shifting across industries. Indeed, we think that our test can, with reasonable confidence, measure whether taxes are under- or overshifted in a particular industry. This is, in our opinion, an important and relevant policy result.

Third, one can easily imagine a more general application of our test. Essentially, a change in excise taxes is an exogenous (at least for an individual firm) shock to its marginal cost. As such, our theory could in principle go through for any exogenous cost shock to firms. This idea could be of interest to antitrust policy, as our test could identify whether exogenous cost shocks are over- or undershifted to consumers depending on market parameters, rather than say, potential collusion. We intend to study the potential implications for antitrust policy in future research.

Finally, we can turn to the welfare implications of our findings. Besley (1989) discusses the welfare effects of commodity taxation in oligopolistic markets. His Proposition 1 (Besley, 1989, p. 366) states that a marginal increase in excise taxes can be welfare improving if $E<0 .{ }^{32}$ The corresponding expression to Besley's $E$ in our model is $(\eta+k) .{ }^{33}$ Hence, a necessary condition for marginal tax changes to be welfare improving is that they are passed on less than proportionally to consumers. This is the case in our sample. Thus marginal increases in excise taxes in the gasoline market in Canada might be welfare improving. Again, we argue that this is, particularly in the current policy discussion, an interesting result and

\footnotetext{
${ }^{32}$ It should be noted that the Proposition 1 in Besley (1989) seems to present a typographic error that we take into account in the text.

${ }^{33}$ Note that Besley (1989) assumes a constant marginal cost, hence in his model $k=1$.
} 
should be explored further in future research.

\section{Concluding remarks}

The Canadian gasoline retail is a concentrated market. Thus, the perfect competition assumption might be misleading when analyzing the effect of taxes on prices. In oligopolistic markets, taxes can be shifted forward less (more) than proportionally to retail prices; a possibility usually denoted by undershifting (overshifting). Generally, whether there is underor overshifting depends on unobservable parameters of the demand and cost functions. In this paper, we devise an empirical test to assess the degree of tax shifting which is based on observables, namely an interaction term between taxes and market structure in a price equation.

We apply our test to the Canadian retail gasoline market. In our sample of monthly observations across 10 cities over the period 1991-1997, we find that taxes are undershifted. The results are remarkably robust to a series of alternative specifications both regarding inference and instrumenting our main variables.

We would argue that our results improve earlier analysis of tax incidence in oligopolistic markets in an important direction. Most of earlier studies in concentrated markets (e.g. gasoline and cigarettes) either explicitly or implicitly assume perfectly competitive markets. We show that such an estimate of tax incidence might be biased when not specifying the model correctly, i.e. when not accounting for the interdependence of market structure and taxes. Further, policy conclusions might be inadequate.

In our data, by not allowing tax incidence to vary with market structure, we find a degree of pass-through of 0.18 . Correctly specifying our model implies a tax incidence, evaluated at the mean, of 0.30 , i.e. an increase of $67 \%$. We also find that the degree of tax shifting depends heavily on market structure. While for the least concentrated markets we cannot reject that taxes are fully passed on to consumer prices, this result is actually inversed for the most concentrated ones where taxes might be fully absorbed by producers. Quite obviously, 
policy conclusions regarding gasoline taxation might be quite different and should depend on the degree of concentration.

Our empirical test is easily applicable to other markets and regions. It requires data showing variation in tax rates and market structure. The Canadian example, where Provinces also set gasoline taxes, is a good illustration of the applicability. The U.S. might be another good example, since States tax gasoline and there is likely also considerable variation in market concentration. Further, our test could have even more general implications and could find its way into further analysis of tax policy and likely even antitrust issues such as collusion. In future work, we aim at linking the vast literature on tax competition with the tax incidence results described in this paper. ${ }^{34}$ Another interesting issue to explore is whether and how our results are affected by the presence of different size firms. ${ }^{35}$

\footnotetext{
${ }^{34}$ See, for example, Hayashi and Boadway (2001), Devereux et al. (2007) and Brulhart and Jametti (2006) among others.

${ }^{35}$ See Vigneault and Wen (2002).
} 


\section{References}

Anderson, Simon P., Andre de Palma, and Brent Kreider (2001) 'Tax incidence in differentiated product oligopoly.' Journal of Public Economics 81(2), 173-192

Baltagi, Badi H. (2009) In 'Econometric analysis of panel data,' 4 ed. (Wiley, Chichester)

Baum, Christopher F, Mark E. Schaffer, and Steven Stillman (2003) 'Instrumental variables and gmm: Estimation and testing.' Stata Journal 3(1), 1-31

Bergman, Michael U., and Niels Lynggård Hansen (2010) 'Are Excise Taxes on Beverages Fully Passed Through to Prices? The Danish Evidence.' Mimeo.

Besley, Timothy J. (1989) 'Commodity taxation and imperfect competition : A note on the effects of entry.' Journal of Public Economics 40(3), 359-367

Besley, Timothy J., and Anne Case (2000) 'Unnatural Experiments? Estimating the Incidence of Endogenous Policies.' Economic Journal 110(467), F672-94

Besley, Timothy J., and Harvey S. Rosen (1999) 'Sales taxes and prices: An empirical analysis.' National Tax Journal 52(2), 157-178

Brulhart, Marius, and Mario Jametti (2006) 'Vertical versus horizontal tax externalities: An empirical test.' Journal of Public Economics 90(10-11), 2027-2062

Cameron, Colin A., Jonah B. Gelbach, and Douglas L. Miller (2008) 'Bootstrap-based improvements for inference with clustered errors.' The Review of Economics and Statistics 90(3), 414-427

Chouinard, Hayley H., and Jeffrey M. Perloff (2007) 'Gasoline price differences: Taxes, pollution regulations, mergers, market power, and market conditions.' The B.E. Journal of Economic Analysis 85 Policy 7(1), 8

DeCicca, Philip, Donald S. Kenkel, and Feng Liu (2010) 'Who Pays Cigarette Taxes? The Impact of Consumer Price Search.' NBER Working Papers 15942, National Bureau of Economic Research, Inc, April

Delipalla, Sophia, and Michael Keen (1992) 'The comparison between ad valorem and specific taxation under imperfect competition.' Journal of Public Economics 49(3), 351-367

Delipalla, Sophia, and Owen O'Donnell (2001) 'Estimating tax incidence, market power and market conduct: The european cigarette industry.' International Journal of Industrial Organization 19(6), 885-908

Devereux, Michael B., Ben. Lockwood, and Michaela. Redoano (2007) 'Horizontal and vertical indirect tax competition: Theory and some evidence from the usa.' Journal of Public Economics 91(3-4), 451-479

DiGiacomo, Marina, Massimiliano Piacenza, and Gilberto Turati (2012) 'Are "Flexible" Taxation Mechanisms Effective in Stabilizing Fuel Prices? An Evaluation Considering the Italian Fuel Markets.' Energy Economics 34(4), 1176-1186 
Fullerton, Don, and Gilbert E. Metcalf (2002) 'Tax incidence.' In 'Handbook of Public Economics,' vol. 4 (Elsevier, North-holland) chapter 26, pp. 1787-1872

Harris, Jeffrey E. (1987) 'The 1983 increase in the federal cigarette excise tax.' Tax Policy and the Economy 1, 87-111

Hausman, Jerry, James H. Stock, and Motohiro Yogo (2005) 'Asymptotic properties of the hahn-hausman test for weak-instruments.' Economics Letters 89(3), 333-342

Hayashi, Masayoshi, and Robin Boadway (2001) 'An empirical analysis of intergovernmental tax interaction: The case of business income taxes in canada.' Canadian Journal of Economics 34(2), 481-503

Karp, Larry S., and Jeffrey M. Perloff (1989) 'Estimating market structure and tax incidence: The japanese television market.' Journal of Industrial Economics 37(3), 225-39

Katz, Michael L., and Harvey S. Rosen (1985) 'Tax analysis in an oligopoly model.' NBER Working Papers 1088, National Bureau of Economic Research, Inc, July

Krzyzaniak, Marian, and Richard A. Musgrave (1963) 'The shifting of the corporation income tax.' (Johns Hopkins Press, Baltimore)

Marion, Justin, and Erich Muehlegger (2011) 'Fuel tax incidence and supply conditions.' Journal of Public Economics 95(9-10), 1202-1212

Moulton, Brent R (1986) 'Random group effects and the precision of regression estimates.' Journal of Econometrics 32(3), 385-397

Moulton, Brent R (1990) 'An illustration of a pitfall in estimating the effects of aggregate variables on micro unit.' The Review of Economics and Statistics 72(2), 334-38

Palazzi, Pamela (2011) 'Taxation and innovation.' OECD Taxation Working Papers, No. 9, OECD Publishing. http://dx.doi.org/10.1787/5kg3h0sf1336-en

Seade, Jesus (1980) 'On the effects of entry.' Econometrica 48(2), 479-89

Seade, Jesus (1985) 'Profitable cost increases and the shifting of taxation : Equilibrium response of markets in oligopoly.' The Warwick Economics Research Paper Series (TWERPS)

Sen, Anindya (2001) 'Overshifting, firm conduct, and tax incidence in concentrated industries: Empirical evidence from the canadian cigarette industry.' Mimeo.

Sen, Anindya, and Peter G.C. Townley (2010) 'Estimating the impacts of outlet rationalization on retail prices, industry concentration, and sales: Empirical evidence from canadian gasoline markets.' Journal of Economics 86 Management Strategy 19(3), 605-633

Stock, James H., and Mark W. Watson (2008) 'Heteroskedasticity-robust standard errors for fixed effects panel data regression.' Econometrica 76(1), 155-174 
Stock, James H., and Motohiro Yogo (2002) 'Testing for weak instruments in linear iv regression.' NBER Working Papers 0284, National Bureau of Economic Research, Inc, November

The Conference Board of Canada (2001) 'The final fifteen feet of hose. The Canadian Gasoline Industry in the Year 2000'

Vigneault, Marianne, and Jean-François Wen (2002) 'Profit taxes and the growth of fringe firms.' The Canadian Journal of Economics 35(4), pp. 717-736

Wooldridge, Jeffrey M. (2003) 'Cluster-sample methods in applied econometrics.' American Economic Review 93(2), 133-138 


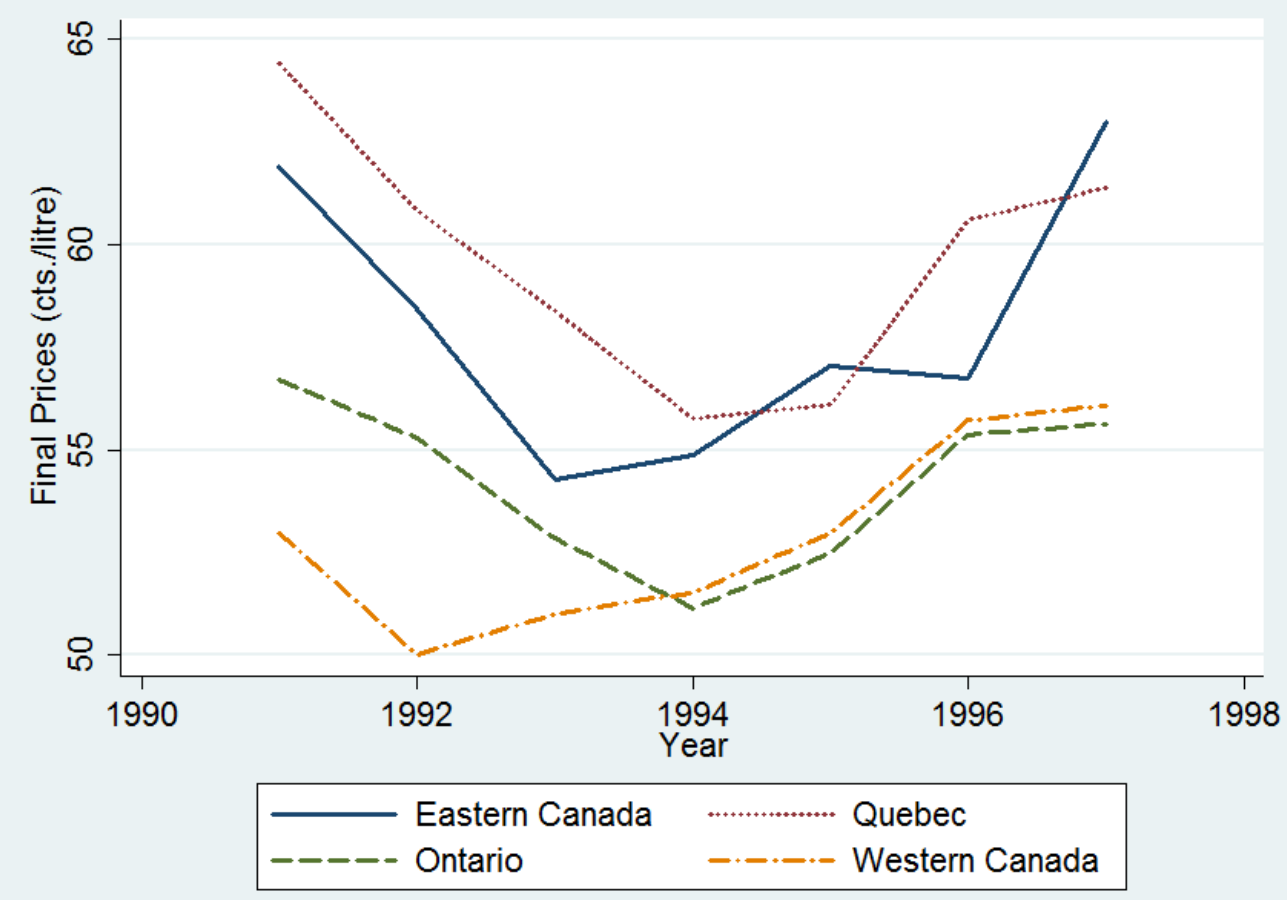

Figure 1: Time Evolution of Prices

Source: The Kent Group 

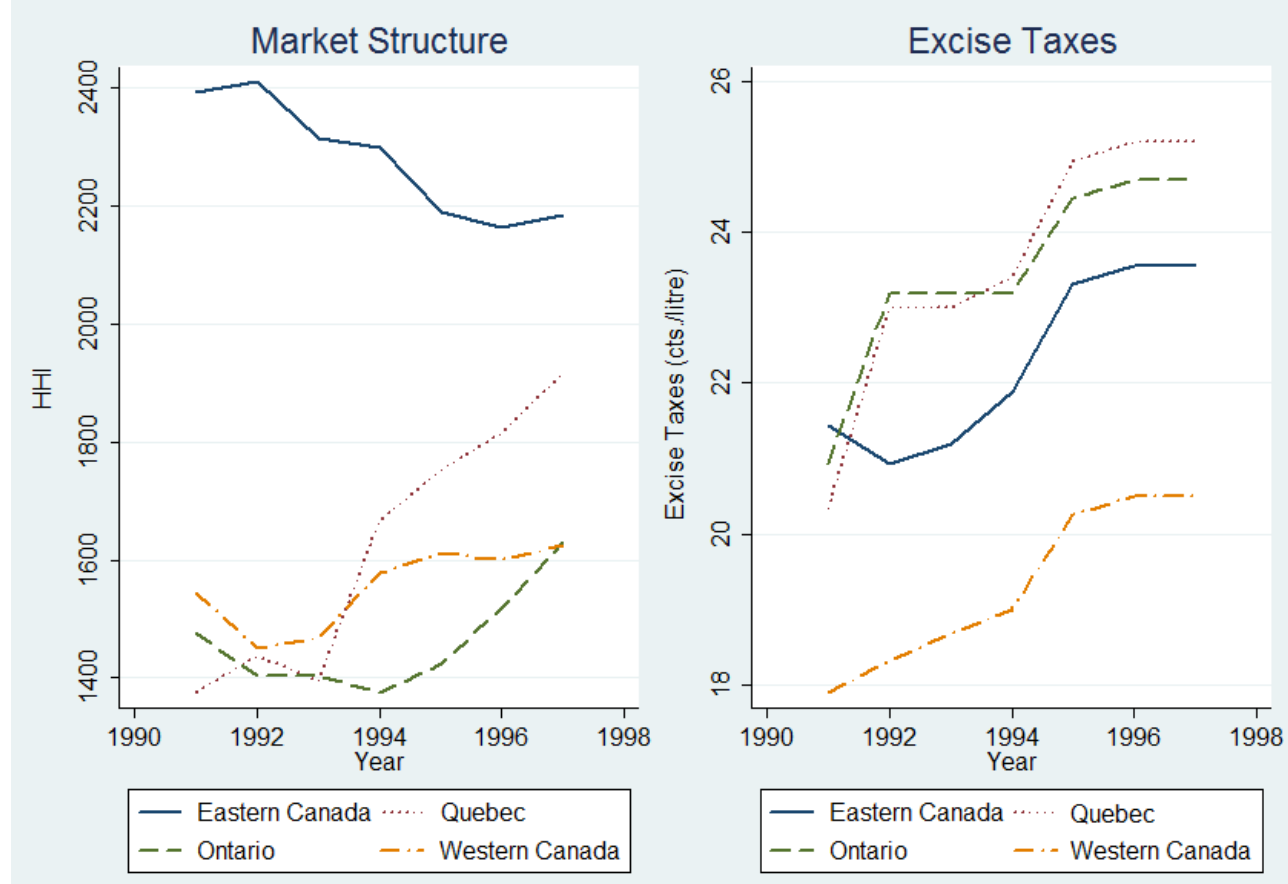

Figure 2: Time Evolution of Market Concentration and Excise taxes

Source: The Kent Group and own calculations 

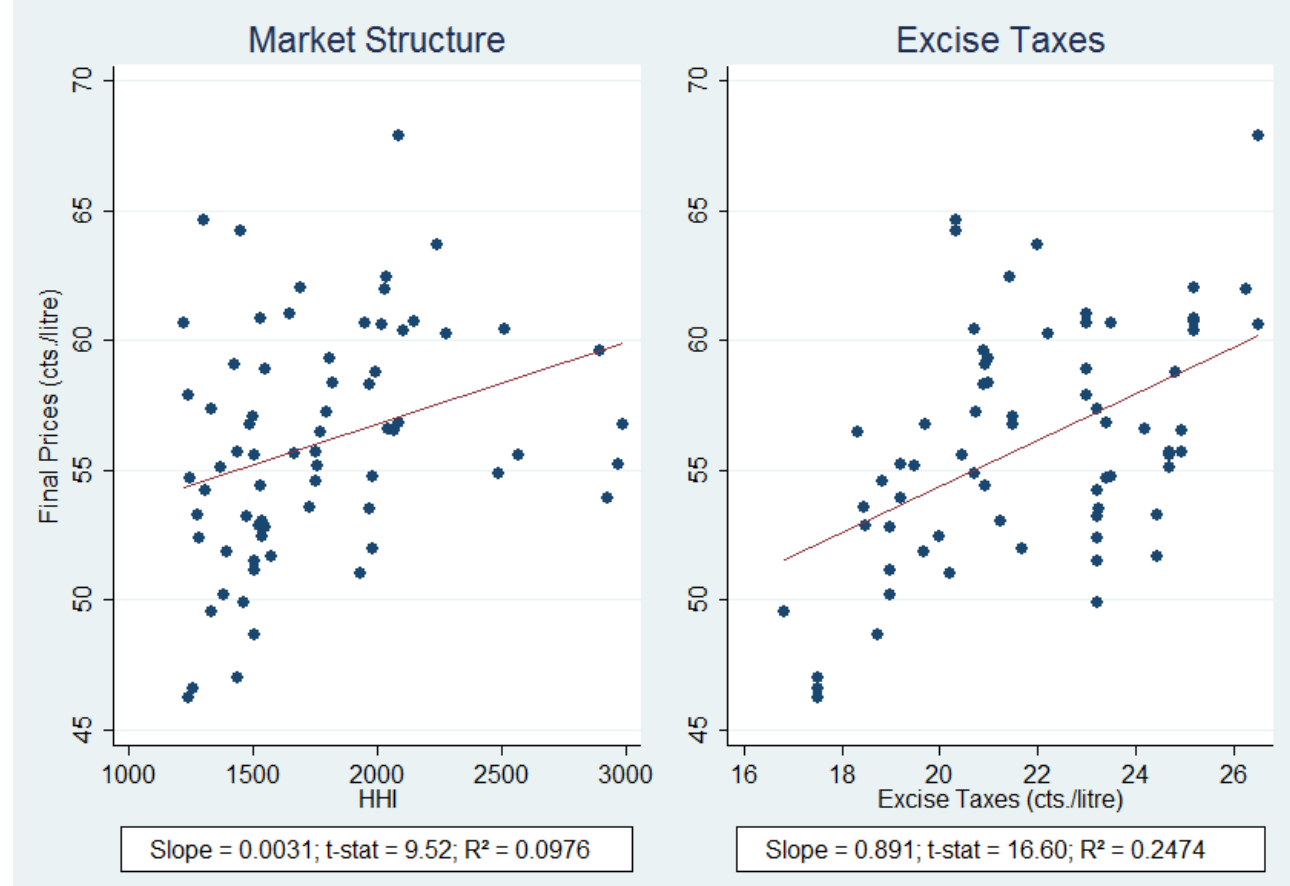

Figure 3: Final Prices, Excise Taxes and Market Structure

Source: The Kent Group and own calculations 


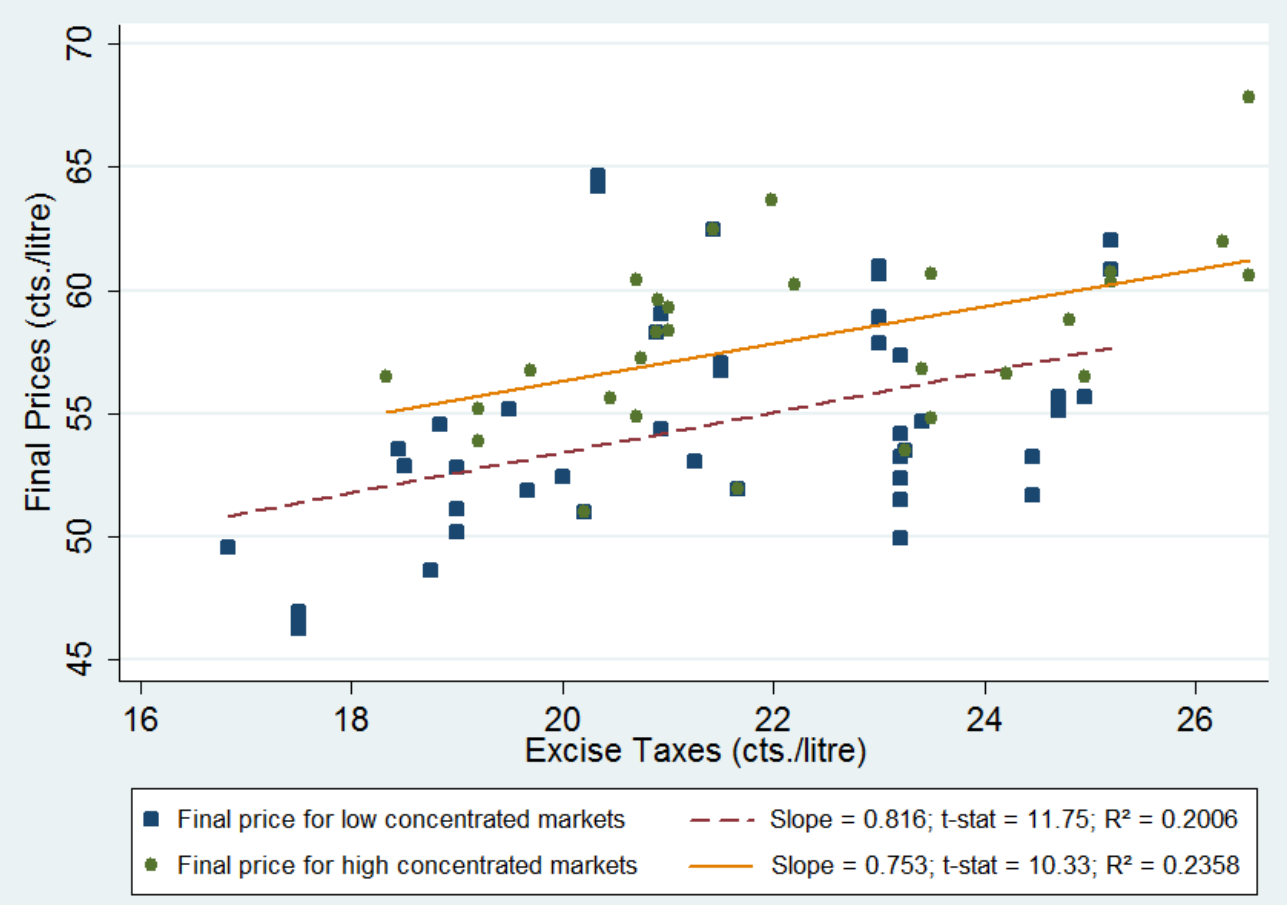

Figure 4: Prices and Taxes for Low and Highly Concentrated Markets

Source: The Kent Group and own calculations 


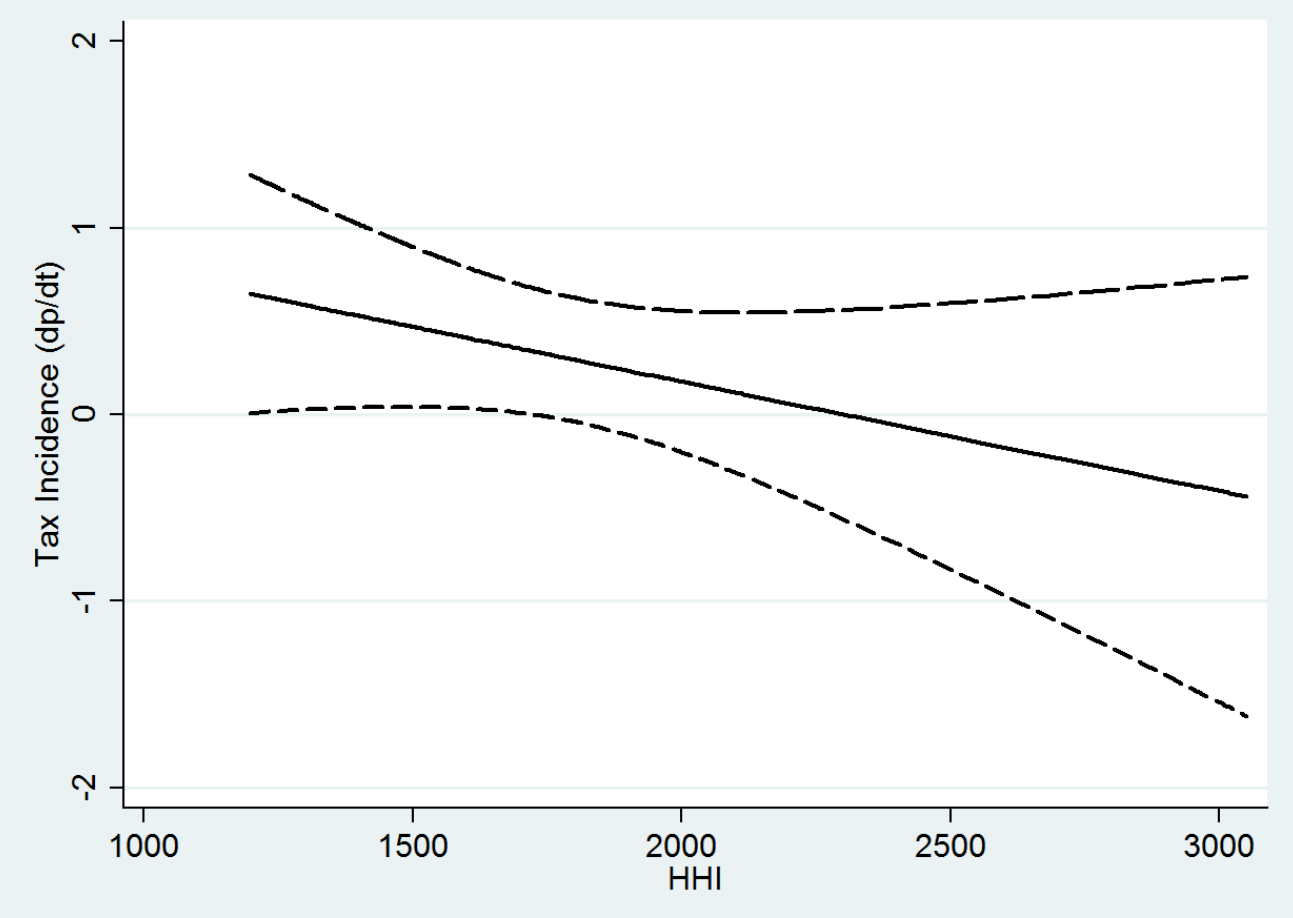

Figure 5: Interdependence of Tax Incidence and Market Structure

Tax incidence (dp/dt)

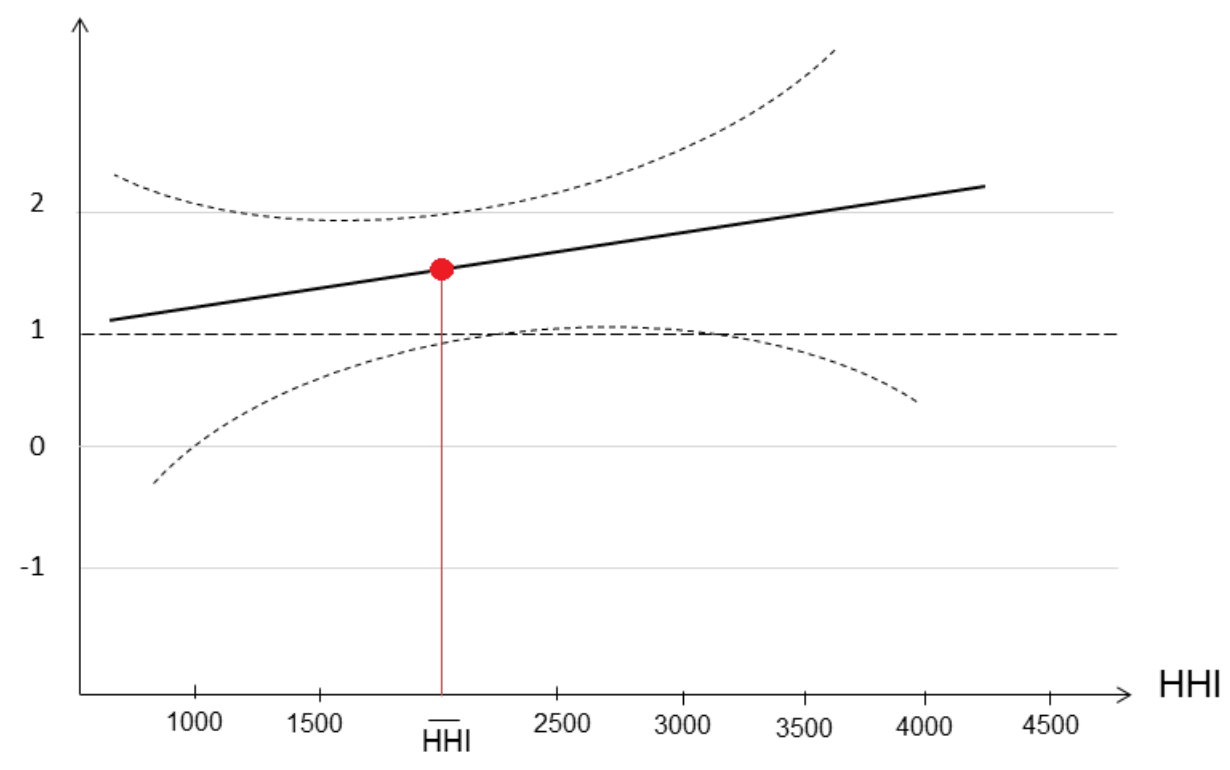

Figure 6: An Alternative Scenario 
Table 1: Summary Statistics

\begin{tabular}{lcccccc}
\hline \multicolumn{1}{c}{ Variable } & Units & $\mathrm{N}$ & Mean & Std. Dev. & Min. & Max. \\
\hline Final retail price including taxes & $\Phi /$ litre & 840 & 56.05 & 5.13 & 38.67 & 72.93 \\
\hline State excise tax & $\$ /$ litre & 840 & 12.78 & 2.30 & 7 & 16.5 \\
Federal and State excise taxes & $\Phi /$ litre & 840 & 21.89 & 2.52 & 15.5 & 26.5 \\
\hline Herfindahl Hirschiman Index & $0-10.000$ & 840 & 1766.7 & 440.5 & 1196.1 & 3051.4 \\
\hline Wholesale price of gasoline & $\$ /$ litre & 840 & 23.29 & 2.88 & 15.24 & 37.9 \\
Per capita consumption of gasoline & litres (in 1.000) & 840 & 0.20 & 0.07 & 0.07 & 0.50 \\
Total number of stations & 1.000 & 840 & 0.34 & 0.35 & 0.05 & 1.42 \\
Population & 100.000 & 840 & 13.22 & 13.37 & 1.28 & 44.99 \\
Prop. population aged 15-24 & $\%$ & 840 & 14.00 & 1.74 & 9.30 & 19.27 \\
Unemployment rate & $\%$ & 840 & 11.39 & 3.28 & 5.4 & 21.5 \\
Average annual income & C (in 1.000) & 840 & 44.71 & 6.69 & 33.8 & 55.8 \\
Share of seats pol. party in power & $\%$ & 840 & 65.71 & 9.46 & 52 & 87.27 \\
Both lib. in power & Dummy & 840 & 0.32 & 0.47 & 0 & 1 \\
Both conserv. in power & Dummy & 840 & 0.60 & 0.24 & 0 & 1 \\
\hline
\end{tabular}


Table 2: No Interaction Term - OLS and Fixed Effects Estimates

\begin{tabular}{|c|c|c|c|c|}
\hline & (1) & (2) & (3) & (4) \\
\hline Excise & $\begin{array}{c}0.180^{*} \\
{[0.0954]}\end{array}$ & $\begin{array}{l}0.188^{* *} \\
{[0.0955]}\end{array}$ & $\begin{array}{c}0.256^{* *} \\
{[0.124]}\end{array}$ & $\begin{array}{c}0.182^{*} \\
{[0.0957]}\end{array}$ \\
\hline HHI & $\begin{array}{l}-5.199 \\
{[7.802]}\end{array}$ & $\begin{array}{l}-5.205 \\
{[7.745]}\end{array}$ & $\begin{array}{l}-5.798 \\
{[7.661]}\end{array}$ & $\begin{array}{l}-5.107 \\
{[7.743]}\end{array}$ \\
\hline Wholesale & $\begin{array}{c}0.669 * * * \\
{[0.0734]}\end{array}$ & $\begin{array}{c}0.640^{* * *} * \\
{[0.0785]}\end{array}$ & $\begin{array}{c}0.644^{* * *} \\
{[0.0791]}\end{array}$ & $\begin{array}{c}0.639 * * * \\
{[0.0785]}\end{array}$ \\
\hline Wholesale_lag1 & $\begin{array}{c}0.562^{* * *} \\
{[0.111]}\end{array}$ & $\begin{array}{c}0.540^{* * *} \\
{[0.113]}\end{array}$ & $\begin{array}{c}0.541^{* * *} \\
{[0.113]}\end{array}$ & $\begin{array}{c}0.540^{* * *} \\
{[0.113]}\end{array}$ \\
\hline Wholesale_lag2 & $\begin{array}{c}-0.241^{* * *} \\
{[0.0847]}\end{array}$ & $\begin{array}{c}-0.225^{* * *} \\
{[0.0833]}\end{array}$ & $\begin{array}{c}-0.229 * * * \\
{[0.0833]}\end{array}$ & $\begin{array}{c}-0.225^{* * *} \\
{[0.0833]}\end{array}$ \\
\hline Unemployment rate & $\begin{array}{c}-0.311^{* * *} \\
{[0.116]}\end{array}$ & $\begin{array}{c}-0.326^{* * *} \\
{[0.114]}\end{array}$ & $\begin{array}{c}-0.356^{* * *} \\
{[0.120]}\end{array}$ & $\begin{array}{c}-0.324^{* * *} \\
{[0.114]}\end{array}$ \\
\hline Population & $\begin{array}{c}0.488^{* *} \\
{[0.192]}\end{array}$ & $\begin{array}{c}0.542^{* * *} \\
{[0.193]}\end{array}$ & $\begin{array}{c}0.571^{* * *} \\
{[0.192]}\end{array}$ & $\begin{array}{c}0.555^{* * *} * \\
{[0.195]}\end{array}$ \\
\hline Prop. aged 15 to 24 & $\begin{array}{c}-0.221^{*} \\
{[0.131]}\end{array}$ & $\begin{array}{c}-0.218^{*} \\
{[0.130]}\end{array}$ & $\begin{array}{c}-0.264^{*} \\
{[0.136]}\end{array}$ & $\begin{array}{c}-0.214^{*} \\
{[0.130]}\end{array}$ \\
\hline Stations & $\begin{array}{c}9.856^{* * *} \\
{[3.170]}\end{array}$ & $\begin{array}{c}10.54^{* * *} \\
{[3.250]}\end{array}$ & $\begin{array}{c}9.698 * * * \\
{[3.413]}\end{array}$ & $\begin{array}{c}10.40^{* * *} \\
{[3.192]}\end{array}$ \\
\hline Gasoline cons. pp & $\begin{array}{l}-0.602 \\
{[3.062]}\end{array}$ & $\begin{array}{l}-1.785 \\
{[3.009]}\end{array}$ & $\begin{array}{l}-1.493 \\
{[3.034]}\end{array}$ & $\begin{array}{l}-1.866 \\
{[3.009]}\end{array}$ \\
\hline Average income & $\begin{array}{l}0.226^{* *} \\
{[0.0888]}\end{array}$ & $\begin{array}{c}0.235^{* * *} \\
{[0.0866]}\end{array}$ & $\begin{array}{c}0.236^{* * * *} \\
{[0.0866]}\end{array}$ & $\begin{array}{c}0.236^{* * *} * \\
{[0.0866]}\end{array}$ \\
\hline City FE & YES & YES & YES & $\mathrm{NO}$ \\
\hline Quarter FE & $\mathrm{NO}$ & YES & YES & YES \\
\hline Time trend & $\mathrm{NO}$ & $\mathrm{NO}$ & YES & $\mathrm{NO}$ \\
\hline City Specific Time trend & $\mathrm{NO}$ & $\mathrm{NO}$ & $\mathrm{NO}$ & YES \\
\hline Observations & 820 & 820 & 820 & 820 \\
\hline$R^{2}$ & 0.7433 & 0.7468 & 0.7471 & 0.7467 \\
\hline
\end{tabular}

Intercept included in all regressions. Standard errors based on robust covariance matrices in brackets. $R^{2}$ overall where applicable.

* $\mathrm{p}<0.10, * * \mathrm{p}<0.05, * * * \mathrm{p}<0.01$ 
Table 3: Main Results - OLS and Fixed Effects Estimates

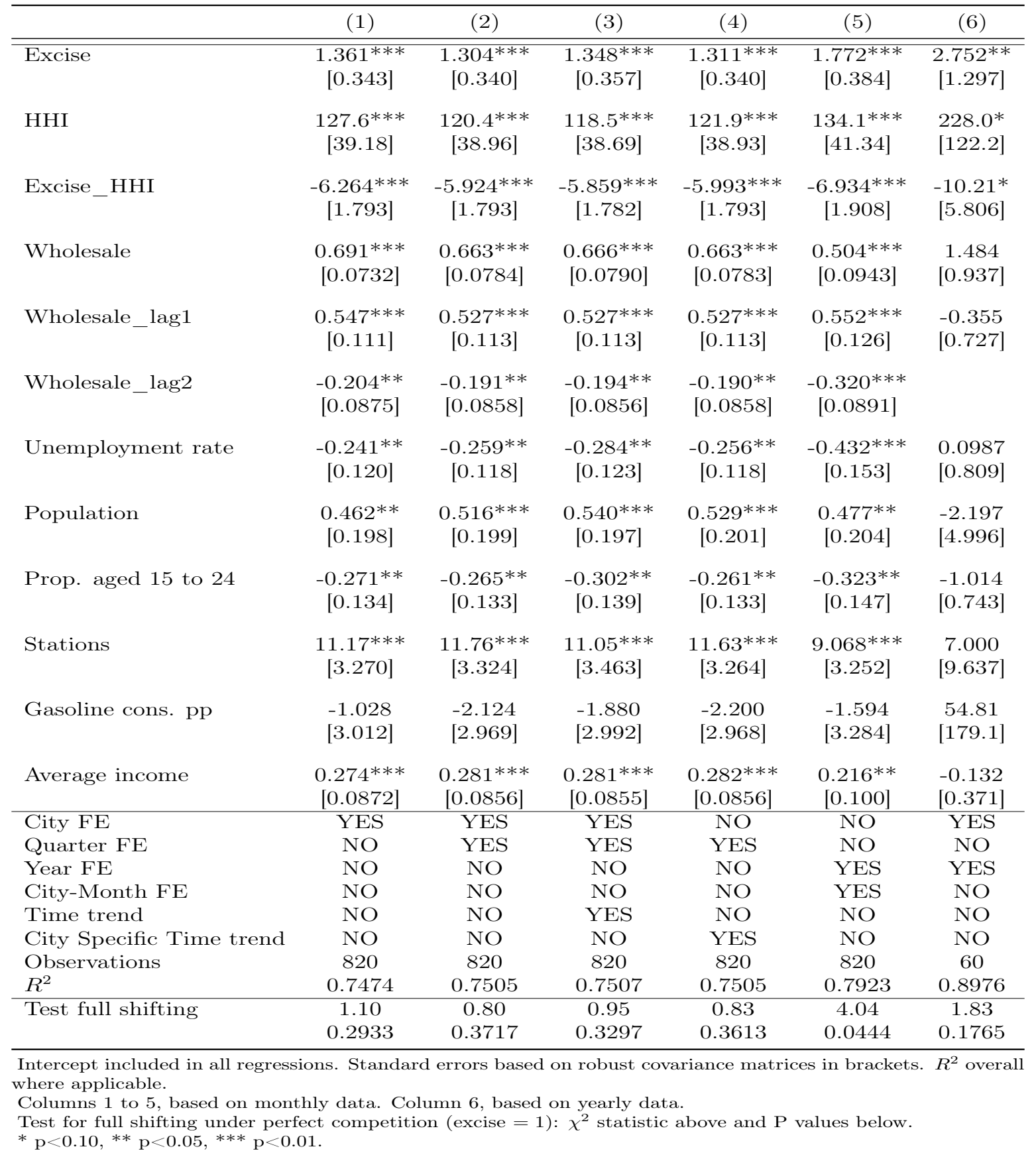


Table 4: Robustness Checks - Inference

\begin{tabular}{lcccccc}
\hline & $(1)$ & $(2)$ & $(3)$ & $(4)$ & $(5)$ & $(6)$ \\
\hline \hline Excise & $1.348^{* * *}$ & $1.187^{* * *}$ & $1.209^{* *}$ & $1.469^{* * *}$ & 1.348 & $1.187^{*}$ \\
& {$[0.357]$} & {$[0.218]$} & {$[0.475]$} & {$[0.324]$} & {$[0.847]$} & {$[0.676]$} \\
HHI & $118.5^{* * *}$ & $93.04^{* * *}$ & $106.2^{* *}$ & $131.5^{* * *}$ & 118.5 & 93.04 \\
& {$[38.69]$} & {$[24.37]$} & {$[53.81]$} & {$[37.37]$} & {$[83.40]$} & {$[72.66]$} \\
Excise_HHI & $-5.859^{* * *}$ & $-3.871^{* * *}$ & $-5.224^{* *}$ & $-6.422^{* * *}$ & -5.859 & -3.871 \\
& {$[1.782]$} & {$[1.229]$} & {$[2.471]$} & {$[1.702]$} & {$[4.608]$} & {$[3.934]$} \\
\hline Covariates & YES & YES & YES & YES & YES & YES \\
Cluster (City) & NO & NO & NO & NO & YES & YES \\
City FE & YES & NO & YES & YES & YES & NO \\
Quarter FE & YES & YES & YES & YES & YES & YES \\
Time trend & YES & YES & YES & YES & YES & YES \\
Observations & 820 & 820 & 840 & 820 & 820 & 820 \\
$R^{2}$ & 0.7507 & 0.7025 & & & 0.497 & \\
\hline Test full shifting & 0.95 & 0.74 & 0.19 & 2.10 & 0.17 & 0.08 \\
& 0.3297 & 0.3904 & 0.6594 & 0.1474 & 0.6906 & 0.7822 \\
\hline
\end{tabular}

Intercept included in all regressions. Standard errors in brackets. $R^{2}$ overall where applicable. Column 1 reproduces column 3 in Table 3, our main specification.

Column 2, based on robust covariance matrices.

Column 3, based on Newey-West standard errors. The lagged values of Wholesale (Wholesale_lag1 and Wholesale_lag2) are excluded because the Newey-West specification has already been computed considering 2 lags in the autocorrelation structure.

Column 4, feasible GLS.

Columns 5, FE, clustered standard errors at the city level.

Columns 6, RE, clustered standard errors at the city level.

Test for full shifting under perfect competition (excise $=1$ ): $\chi^{2}$ (for columns 1, 2, 4 and 6) and $\mathrm{F}$-statistics (for columns 3 and 5 ) above and $\mathrm{P}$ values below.

$* \mathrm{p}<0.10, * * \mathrm{p}<0.05, * * * \mathrm{p}<0.01$ 
Table 5: Robustness Checks - IV-2SLS

\begin{tabular}{lcccccc}
\hline & $(1)$ & $(2)$ & $(3)$ & $(4)$ & $(5)$ & $(6)$ \\
\hline \hline Excise & $1.797^{* * *}$ & $8.830^{* * *}$ & $9.088^{* * *}$ & $1.319^{* * *}$ & $3.249^{* * *}$ & $3.345^{* * *}$ \\
& {$[0.589]$} & {$[1.893]$} & {$[1.960]$} & {$[0.316]$} & {$[1.013]$} & {$[1.016]$} \\
HHI & $171.7^{* *}$ & $867.6^{* * *}$ & $897.7^{* * *}$ & $108.5^{* * *}$ & $314.2^{* * *}$ & $324.5^{* * *}$ \\
& {$[66.28]$} & {$[195.6]$} & {$[204.2]$} & {$[36.18]$} & {$[108.9]$} & {$[109.2]$} \\
Excise_HHI & $-8.281^{* * *}$ & $-41.32^{* * *}$ & $-42.70^{* * *}$ & $-4.635^{* *}$ & $-14.78^{* * *}$ & $-15.28^{* * *}$ \\
& {$[3.018]$} & {$[9.119]$} & {$[9.499]$} & {$[1.805]$} & {$[5.376]$} & {$[5.392]$} \\
\hline Covariates & YES & YES & YES & YES & YES & YES \\
City FE & YES & YES & YES & NO & NO & NO \\
Quarter FE & YES & YES & YES & YES & YES & YES \\
Time trend & YES & YES & YES & YES & YES & YES \\
Observations & 820 & 820 & 820 & 820 & 820 & 820 \\
$R^{2}$ & 0.742 & 0.589 & 0.579 & 0.696 & 0.670 & 0.668 \\
\hline Test full shifting & 1.83 & 17.12 & 17.03 & 1.02 & 4.93 & 5.33 \\
& 0.1759 & 0.0000 & 0.0000 & 0.3137 & 0.0265 & 0.0209 \\
Sargan Test & 3.157 & 6.935 & 8.036 & 2.395 & 7.718 & 9.590 \\
& 0.0756 & 0.0312 & 0.0453 & 0.1217 & 0.0211 & 0.0224 \\
Weak identif.test & 160.77 & 13.24 & 7.93 & 380.62 & 18.82 & 11.34 \\
\hline
\end{tabular}

Intercept included in all regressions. Standard errors in brackets in brackets. $R^{2}$ overall where applicable. Columns 1,2 and 3, with FE-2SLS. Columns 4, 5 and 6, with RE-2SLS.

Columns 1 and 4: HHI instrumented using all exogenous regressors plus lagged values of HHI $\left(H H I_{t-1}\right.$ and $H H I_{t-2}$ ).

Columns 2 and 5: Excise instrumented using all exogenous regressors plus the share of seats of the political party in power in each province and a dummy indicating whether the political party in power is the same at both the federal and state levels.

Columns 3 and 6: Both excise and HHI instrumented using the instruments mentioned above.

Test for fully shifting under perfect competition $($ excise $=1): \chi^{2}$ above and $\mathrm{P}$ values below.

Sargan test of overidentifying restrictions: $\chi^{2}$ above and $\mathrm{P}$ values below.

Weak identification test: 1st-stage F-statistic except for columns 3 and 6 where we provide the CraggDonald Wald F-statistic to be compared with the values given by Stock and Yogo (2002).

$* \mathrm{p}<0.10, * * \mathrm{p}<0.05, * * * \mathrm{p}<0.01$ 


\section{QUADERNI DELLA FACOLTÀ}

1998:

P. Balestra, Efficient (and parsimonious) estimation of structural dynamic error component models

1999:

M. Filippini, Cost and scale efficiency in the nursing home sector : evidence from Switzerland

L. Bernardi, I sistemi tributari di oggi : da dove vengono e dove vanno

L.L. Pasinetti, Economic theory and technical progress

G. Barone-Adesi, K. Giannopoulos, L. Vosper, VaR without correlations for portfolios of derivative securities

G. Barone-Adesi, Y. Kim, Incomplete information and the closed-end fund discount

G. Barone-Adesi, W. Allegretto, E. Dinenis, G. Sorwar, Valuation of derivatives based on CKLS interest rate models

M. Filippini, R. Maggi, J. Mägerle, Skalenerträge und optimale Betriebsgrösse bei den schweizerische Privatbahnen

E. Ronchetti, F. Trojani, Robust inference with GMM estimators

G.P. Torricelli, I cambiamenti strutturali dello sviluppo urbano e regionale in Svizzera e

nel Ticino sulla base dei dati dei censimenti federali delle aziende 1985, 1991 e 1995

2000:

E. Barone, G. Barone-Adesi, R. Masera, Requisiti patrimoniali, adeguatezza del capitale e gestione del rischio

G. Barone-Adesi, Does volatility pay?

G. Barone-Adesi, Y. Kim, Incomplete information and the closed-end fund discount

$\mathrm{R}$. Ineichen, Dadi, astragali e gli inizi del calcolo delle probabilità

W. Allegretto, G. Barone-Adesi, E. Dinenis, Y. Lin, G. Sorwar, A new approach to check the free boundary of single factor interest rate put option

G.D.Marangoni, The Leontief Model and Economic Theory

B. Antonioli, R, Fazioli, M. Filippini, // servizio di igiene urbana italiano tra concorrenza e monopolio

L. Crivelli, M. Filippini, D. Lunati. Dimensione ottima degli ospedali in uno Stato federale

L. Buchli, M. Filippini, Estimating the benefits of low flow alleviation in rivers: the case of the Ticino River

L. Bernardi, Fiscalità pubblica centralizzata e federale: aspetti generali e il caso italiano attuale

M. Alderighi, R. Maggi, Adoption and use of new information technology

F. Rossera, The use of log-linear models in transport economics: the problem of

commuters' choice of mode

2001:

M. Filippini, P. Prioni, The influence of ownership on the cost of bus service provision in

Switzerland. An empirical illustration

B. Antonioli, M. Filippini, Optimal size in the waste collection sector

B. Schmitt, La double charge du service de la dette extérieure

L. Crivelli, M. Filippini, D. Lunati, Regulation, ownership and efficiency in the Swiss

nursing home industry

S. Banfi, L. Buchli, M. Filippini, Il valore ricreativo del fiume Ticino per i pescatori

L. Crivelli, M. Filippini, D. Lunati, Effizienz der Pflegeheime in der Schweiz 
2002:

B. Antonioli, M. Filippini, The use of a variable cost function in the regulation of the Italian water industry

B. Antonioli, S. Banfi, M. Filippini, La deregolamentazione del mercato elettrico svizzero e implicazioni a breve termine per l'industria idroelettrica

M. Filippini, J. Wild, M. Kuenzle, Using stochastic frontier analysis for the access price regulation of electricity networks

G. Cassese, On the structure of finitely additive martingales

2003:

M. Filippini, M. Kuenzle, Analisi dell'efficienza di costo delle compagnie di bus italiane e svizzere

C. Cambini, M. Filippini, Competitive tendering and optimal size in the regional bus transportation industry

L. Crivelli, M. Filippini, Federalismo e sistema sanitario svizzero

L. Crivelli, M. Filippini, I. Mosca, Federalismo e spesa sanitaria regionale : analisi empirica per i Cantoni svizzeri

M. Farsi, M. Filippini, Regulation and measuring cost efficiency with panel data models : application to electricity distribution utilities

M. Farsi, M. Filippini, An empirical analysis of cost efficiency in non-profit and public nursing homes

F. Rossera, La distribuzione dei redditi e la loro imposizione fiscale : analisi dei dati fiscali svizzeri

L. Crivelli, G. Domenighetti, M. Filippini, Federalism versus social citizenship :

investigating the preference for equity in health care

M. Farsi, Changes in hospital quality after conversion in ownership status

G. Cozzi, O. Tarola, Mergers, innovations, and inequality

M. Farsi, M. Filippini, M. Kuenzle, Unobserved heterogeneity in stochastic cost frontier models : a comparative analysis

2004:

G. Cassese, An extension of conditional expectation to finitely additive measures

$\mathrm{S}$. Demichelis, O. Tarola, The plant size problem and monopoly pricing

F. Rossera, Struttura dei salari 2000 : valutazioni in base all'inchiesta dell'Ufficio federale

di statistica in Ticino

M. Filippini, M. Zola, Economies of scale and cost efficiency in the postal services :

empirical evidence from Switzerland

F. Degeorge, F. Derrien, K.L. Womack, Quid pro quo in IPOs : why book-building is

dominating auctions

M. Farsi, M. Filippini, W. Greene, Efficiency measurement in network industries :

application to the Swiss railway companies

L. Crivelli, M. Filippini, I. Mosca, Federalism and regional health care expenditures : an

empirical analysis for the Swiss cantons

S. Alberton, O. Gonzalez, Monitoring a trans-border labour market in view of liberalization : the case of Ticino

M. Filippini, G. Masiero, K. Moschetti, Regional differences in outpatient antibiotic consumption in Switzerland

A.S. Bergantino, S. Bolis, An adaptive conjoint analysis of freight service alternatives :

evaluating the maritime option

2005:

M. Farsi, M. Filippini, An analysis of efficiency and productivity in Swiss hospitals

M. Filippini, G. Masiero, K. Moschetti, Socioeconomic determinants of regional

differences in outpatient antibiotic consumption : evidence from Switzerland 
2006:

M. Farsi, L. Gitto, A statistical analysis of pain relief surgical operations

M. Farsi, G. Ridder, Estimating the out-of-hospital mortality rate using patient discharge data

S. Banfi, M. Farsi, M. Filippini, An empirical analysis of child care demand in Switzerland

L. Crivelli, M. Filippini, Regional public health care spending in Switzerland : an empirical analysis

M. Filippini, B. Lepori, Cost structure, economies of capacity utilization and scope in Swiss higher education institutions

M. Farsi, M. Filippini, Effects of ownership, subsidization and teaching activities on hospital costs in Switzerland

M. Filippini, G. Masiero, K. Moschetti, Small area variations and welfare loss in the use of antibiotics in the community

A. Tchipev, Intermediate products, specialization and the dynamics of wage inequality in the US

A. Tchipev, Technological change and outsourcing : competing or complementary explanations for the rising demand for skills during the 1980s?

2007:

M. Filippini, G. Masiero, K. Moschetti, Characteristics of demand for antibiotics in primary care : an almost ideal demand system approach

G. Masiero, M. Filippini, M. Ferech, H. Goossens, Determinants of outpatient antibiotic consumption in Europe : bacterial resistance and drug prescribers

R. Levaggi, F. Menoncin, Fiscal federalism, patient mobility and the soft budget constraint : a theoretical approach

M. Farsi, The temporal variation of cost-efficiency in Switzerland's hospitals : an application of mixed models

2008

M. Farsi, M. Filippini, D. Lunati, Economies of scale and efficiency measurement in Switzerland's nursing homes

A. Vaona, Inflation persistence, structural breaks and omitted variables : a critical view

A. Vaona, The sensitivity of non parametric misspecification tests to disturbance autocorrelation

A. Vaona, STATA tip : a quick trick to perform a Roy-Zellner test for poolability in STATA

A. Vaona, R. Patuelli, New empirical evidence on local financial development and growth

C. Grimpe, R. Patuelli, Knowledge production in nanomaterials : an application of spatial filtering to regional system of innovation

A. Vaona, G. Ascari, Regional inflation persistence : evidence from Italy

M. Filippini, G. Masiero, K. Moschetti, Dispensing practices and antibiotic use

T. Crossley, M. Jametti, Pension benefit insurance and pension plan portfolio choice

R. Patuelli, A. Vaona, C. Grimpe, Poolability and aggregation problems of regional innovation data : an application to nanomaterial patenting

J.H.L. Oud, H. Folmer, R. Patuelli, P. Nijkamp, A spatial-dependence continuous-time model for regional unemployment in Germany

2009:

J.G. Brida, S. Lionetti, W.A. Risso, Long run economic growth and tourism : inferring from Uruguay

R. Patuelli, D.A. Griffith, M. Tiefelsdorf, P. Nijkamp, Spatial filtering and eigenvector stability : space-time models for German unemployment data

R. Patuelli, A. Reggiani, P. Nijkamp, N. Schanne, Neural networks for cross-sectional employment forecasts : a comparison of model specifications for Germany

A. Cullmann, M. Farsi, M. Filippini, Unobserved heterogeneity and International

benchmarking in public transport

M. Jametti, T. von Ungern-Sternberg, Hurricane insurance in Florida

S. Banfi, M. Filippini, Resource rent taxation and benchmarking : a new perspective for the Swiss hydropower sector 
S. Lionetti, R. Patuelli, Trading cultural goods in the era of digital piracy

M. Filippini, G. Masiero, K. Moschetti, Physician dispensing and antibiotic prescriptions

2010:

R. Patuelli, N. Schanne, D.A. Griffith, P. Nijkamp, Persistent disparities in regional unemployment : application of a spatial filtering approach to local labour markets in Germany

K. Deb, M. Filippini, Public bus transport demand elasticities in India

L. Masiero, R. Maggi, Estimation of indirect cost and evaluation of protective measures for infrastructure vulnerability : a case study on the transalpine transport corridor

L. Masiero, D.A. Hensher, Analyzing loss aversion and diminishing sensitivity in a freight transport stated choice experiment

L. Masiero, D.A. Hensher, Shift of reference point and implications on behavioral reaction to gains and losses

J.M. Rose, L. Masiero, A comparison of prospect theory in WTP and preference space

M. Filippini, M. Koller, U. Trinkner, Do opening hours and unobserved heterogeneity affect economies of scale and scope in postal outlets?

G. Guerra, R. Patuelli, R. Maggi, Ethnic concentration, cultural identity and immigrant self-employment in Switzerland

S. Lionetti, Tourism productivity : incentives and obstacles to fostering growth

G. Guerra, R. Patuelli, The influence of role models on immigrant self-employment : a spatial analysis for Switzerland

M. Filippini, L. Gonzalez, G. Masiero, Estimating dynamic consumption of antibiotics using panel data : the shadow effect of bacterial resistance

2011:

L. Masiero, J.L. Nicolau, Price sensitivity to tourism activities : looking for determinant factors

L. Masiero, J.L. Nicolau, Finding similar price preferences on tourism activities

L. Masiero, R. Maggi, Accounting for WTP/WTA discrepancy in discrete choice models : discussion of policy implications based on two freight transport stated choice experiments

L. Masiero, J.M. Rose, The role of the reference alternative in the specification of asymmetric discrete choice models

D. Engel, T. Mitze, R. Patuelli, J. Reinkowski, Does the support of innovative clusters sustainably foster R\&D activity? Evidence from the German BioRegio and BioProfile contests

L. González, G. Masiero, Disentangling spillover effects of antibiotic consumption : a spatial panel approach

M. Jametti, M. Joanis, Electoral competition as a determinant of fiscal decentralization

2012:

Quaderno n. 12-01

G. Guerra, The role of job satisfaction in transitions into self-employment

Quaderno n. 12-02

M. Filippini, L.G. González Ortiz, G. Masiero, Assessing the impact of antibiotic policies in Europe

Quaderno n. 12-03

L. Di Giorgio, M. Filippini, G. Masiero, The impact of the institutional form on the cost efficiency of nursing homes

Quaderno n. 12-04 
M. Filippini, G. Masiero, D. Medici, The demand for school meals : an analysis of stated choices by Swiss househols

Quaderno n. 12-05

L. Masiero, J. Zoltan, Tourists intra-destination visits and transportation mode : a bivariate model

Quaderno n. 12-06

M. Filippini, M. Koller, Cost efficiency measurement in postal delivery networks

Quaderno n. 12-07

S. Galletta, M. Jametti, How to tame two leviathans? Revisiting the effect of direct democracy on local public expenditure

Quaderno n. 12-08

S. Galletta, M. Jametti, A. Redonda, Highway to economic growth? Competition in public works tenders in the Democratic Republic of Congo

2013:

Quaderno n. 13-01

M. Jametti, A. Redonda, A. Sen, The power to pass on taxes : a test for tax shifting based on observables 